\title{
Bioactive scaffolds based on elastin-like materials for wound healing
}

J. Carlos Rodríguez-Cabello ${ }^{1}$, I. González de Torre ${ }^{1}$, A. Ibañez-Fonzeca ${ }^{1}$ M. Alonso ${ }^{1}$,

${ }^{1}$ BIOFORGE, CIBER-BBN, Edificio Lucia, Universidad de Valladolid, Paseo Belén 19, 47011, Valladolid, Spain

Prof. José Carlos Rodríguez Cabello

G.I.R BIOFORGE, Universidad de Valladolid

Paseo de Belén 19

47011, Valladolid, Spain

E-mail: roca@bioforge.uva.es

Dr. Israel Gonzalez de Torre

G.I.R BIOFORGE, Universidad de Valladolid

Paseo Belén 9 A,

47011, Valladolid, Spain.

E-mail: igonzalez@bioforge.uva.es

Dr. Arturo Ibañez-Fonseca

G.I.R BIOFORGE, Universidad de Valladolid

Paseo Belén 9 A,

47011, Valladolid, Spain.

E-mail: aibanez@bioforge.uva.es

Prof. Matilde Alonso

G.I.R BIOFORGE, Universidad de Valladolid

Paseo de Belén 19

47011, Valladolid, Spain

E-mail: malonso@bioforge.uva.es

Keywords: Wound healing, Elastin like recombinamers, tropoelastin, scaffolds, hydrogels

\section{Abstract}

Wound healing is a complex process that, in healthy tissues, starts immediately after the injury. Even though it is a natural well-orchestrated process, large trauma wounds, or injuries caused by acids or other chemicals, usually produce a non-elastic deformed tissue that not only have biological reduced properties but a clear aesthetic effect. One of the main 
drawbacks of the scaffolds used for wound dressing is the lack of elasticity, driving to nonelastic and contracted tissues. In the last decades, elastin based materials have gained in importance as biomaterials for tissue engineering applications due to their good cyto- and biocompatibility, their ease handling and design, production and modification. Synthetic elastin or elastin like-peptides (ELPS) are the two main families of biomaterials that try to mimic the outstanding properties of natural elastin, elasticity among others; although there are no in vivo studies that clearly support that these two families of elastin based materials improve the elasticity of the artificial scaffolds and of the regenerated skin. Within the next pages a review of the different forms (coacervates, fibres, hydrogels and biofunctionalized surfaces) in which these two families of biomaterials can be processed to be applied in the wound healing field have been done. Here, we explore the mechanical and biological properties of these scaffolds as well as the different in vivo approaches in which these scaffolds have been used.

\section{Contents}

1. Introduction

2. Tropoelastin-based materials for wound healing

2.1. Electrospun tropoelastin-based scaffolds

2.2. Tropoelastin-based hydrogels

2.3. $\alpha$-Elastin-based hydrogels

3. Elastin-like recombinamers (ELRs) as wound-healing materials

3.1. ELR nanoparticles and coacervates

3.2. ELR-based electrospun fibres

3.3. ELR-based hydrogels

3.4. Surface treatment with ELRs

4. Conclusion and future perspectives

\section{Introduction}

An elastomer is any polymeric material that is capable to recover its original size and shape after being stretched to great extent, some proteins can be classified as elastomeric materials[1]. These elastomeric proteins can be found in the plant and animal kingdom as for instance tinin, elastin, silk, resilin in animals or even in gluten proteins from plants[2]. All these materials have elastic properties directly related to their polymeric structure. Biological 
elastomeric materials have to satisfy two criteria[3], monomers must be flexible and conformationally free, and second, they have to forma a network after crosslinking[4]. All these materials present attractive properties to be employed in tissue engineering. For instance, resillin and resilin-like proteins[5] exhibits mechanical properties similar to the native vocal fold[6] and human cartilage[7], even mechanical properties useful for cardiovascular applications[8]. Silk and silk-like peptides are mainly composted of $\beta$-sheet structures that permit tight packing of stacked sheets of hydrogen bonded anti-parallel chains of the polymers. Large hydrophobic domains interspaced with smaller hydrophilic domains foster the assembly of silk and the strength and resiliency of silk fibers[9]. These materials have been well studied and extensively applied in the tissue engineering field[10-15]. Elastin is another of these elastomeric proteins, and precisely we will focus our attention in this review in the properties and benefits that elastin based materials offers to the wound healing field.

Usually, elastin gene possesses 36 exons and some of these exons codify hydrophobic sequences of aminoacid while other exons encode lysine rich sequences[16]. This pattern is commonly shared between animal species although hydrophobic segments exhibit quite variability without affecting functionality. On the other hand, sequences coded by exons 33 and 36 as well as lysyl rich parts are well conserved[17].

Elastin is an insoluble protein formed by the crosslinking of its soluble precursor tropoelastin. Tropoelastin is a protein of 750 to 800 residues[17]. Aliphatic residues, such as proline (P), alanine $(A)$, valine $(V)$, leucine $(L)$, isoleucine $(I)$ and glycine $(G)$ are abundant in the hydrophobic sequences of the protein, which are highly repetitive. The cross-linking domains of tropoelastin contain lysyl residues within proline-rich regions. Hydroxylation of about $1 \%$ prolyl residues is one of the post-translational modifications of tropoelastin[18]. This modification is particularly abundant in the VGVPG[19]. 
Elastogenesis is a complex process that starts inside the cell where the tropoelastin is synthetized and protected by galactolectin (elastin-binding protein) from a premature intracellular aggregation[20]. This chaperon of galactolectin interact with galactosugars in the extracellular space releasing the tropoelastin molecule. C-terminal end of tropoelastin interact with the $\mathrm{N}$-terminal part of the microfibrillar-associated glycoprotein inducing an alignment of the tropoelastin, which have been considered crucial for a correct elastogenesis[21, 22]. Once aligned, most of the lysyl residues of the tropoelastin molecule are deaminated and oxidized to allysine following the action of the $\mathrm{Cu}^{2+}$ requiring lysyl oxidase. Finally, the crosslinks are formed by the reaction of the allysines with unmodified lysine residues or with themselves, leading to the insolubilization of tropoelastin chains as the elastin network grows[23]. Therefore, mature elastin is an insoluble polymer formed by the crosslinking of several tropoelastin molecules. Mature elastin is extremely stable with a very low turn-over that can be considered that elastin last for the entire lifespan of the host[21]. This crosslinking produces a stable insolubility that prevents elastin from being manipulated and therefore considered as a suitable molecule for use in tissue engineering or other biological applications [24].

According to the Urry's model, the elasticity of elastin is coded by a sequence of five amino acids (valine-proline-glycine-valine-glycine, VPGVG). This pentamer forms a $\beta$-turn with PG at the corner of the turn and a $4 \rightarrow 1$ hydrogen bond connecting the ceto group of the first valine to the amino group of the fourth valine along the sequence. The repetition of these $\beta$-turn produce a helical arrangement, called $\beta$-spiral where the $\beta$-turns act as spacers between the turns of the spirals. VG segments are suspended between the $\beta$-turns. These dipeptides allows large-amplitude, low-frequency vibrations. Reductions in the amplitude of the vibrations causes large decrease in the entropy of the segment, providing the driving force for return to the relaxed state. This fact is the responsible for the elastic behaviour of the protein[21, 25]. 
Elastin is a unique extracellular matrix protein that provides the necessary elastic and resilient properties to organs and tissues, especially those that require elasticity or are involved in cycles of elongation and shrinkage[26]. Elastin plays an essential role in the functionality of many tissues, for example lungs, blood vessels, heart valves and skin, amongst others[27], despite not forming the majority of these tissues. Indeed, only around $2-4 \%$ of the dry weight of human skin is provided by elastin[28]. Nevertheless, despite its relatively low abundance, elastin has important structural functions, provides mechanical support, and is involved in many cell-signalling processes[24, 29].

While wound healing in fetal development is a scar-less process, mainly due to an attenuated inflammatory response, an abundance of skin morphogenetic factors and full restoral of the normal skin architecture[30-33]; in adults this process is governed by four main stages, namely haemostasis, inflammation, proliferation and remodelling[34], therefore if no other factors impede the normal wound healing process, a natural scar tissue will be obtained in adults[29, 34]. Under normal conditions, and immediately after the injury, bleeding causes the spillage of blood components, thus forming a blood clot that re-establishes haemostasis and provides a temporary ECM within a few seconds[29, 35]. Even at this very early stage, key actors in this process, especially platelets, neutrophils and macrophages, have begun to perform their role. Beside their containment, cleaning and protecting duties, these cells start to produce and segregate different chemoattractants, such as transforming grow factor $\beta 1$ (TGF- $\beta 1$ ), transforming grow factor $\alpha$ (TGF- $\alpha$ ), fibroblast growth factor (FGF), platelet derived growth factor (PDGF-BB) and vascular endothelial growth factor (VEGF), amongst others [29, 35]. All these cytokines induce the arrival of monocytes, more macrophages, fibroblasts and endothelial cells, which start to remodel the provisional ECM by secreting different activators, such as urokinase-type plasminogen activator ( $\mathrm{u}-\mathrm{PA})$ and tissue plasminogen activator (t-PA), that induce the production of proteinases such as collagenase 1 , stromelysin 1 , collagenase 3 and gelatinase $A[35]$. 

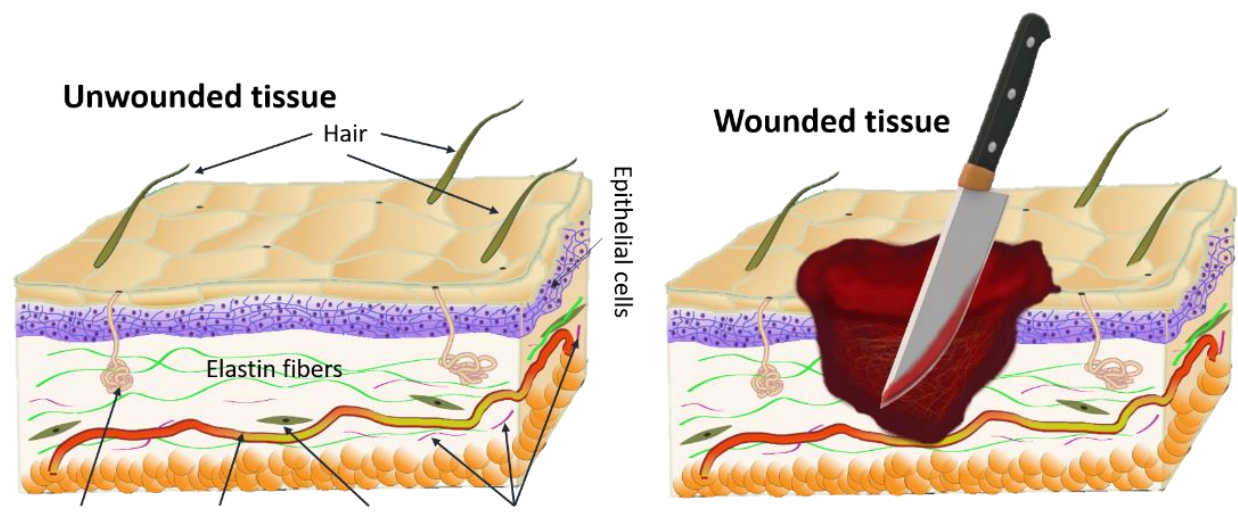

Sweat gland Blood vessel Fibroblast Collagen fibers

\section{Inflammation process}

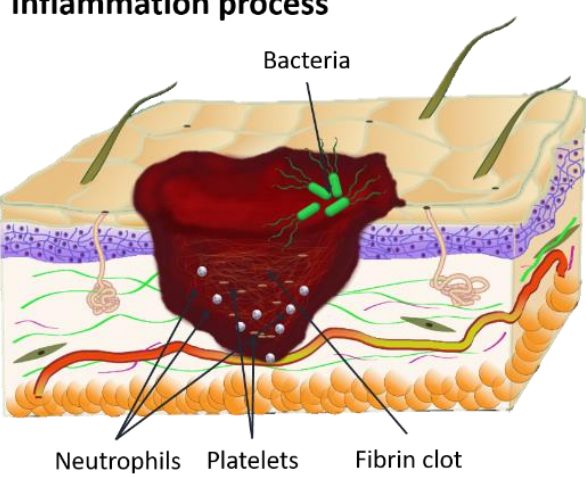

\section{Reparation stage}

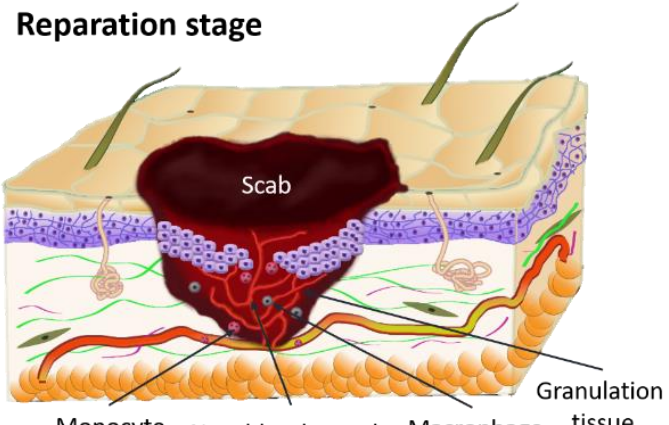

Monocyte New blood vessels Macrophage tissue

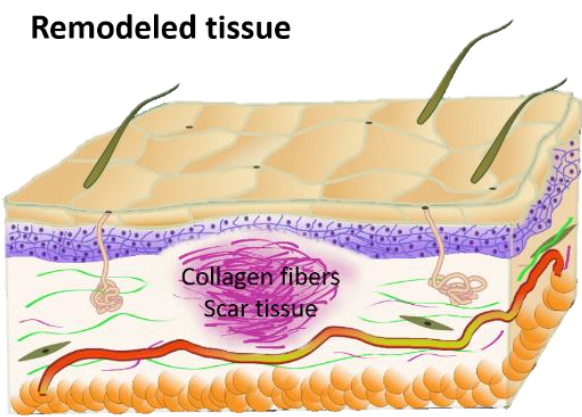

Fig. 1. Normal steps in wound healing process. During the inflammation process a fibrin clot is formed and inflammatory cells arrive to the damage area. Then a provisional extracellular matrix is formed and new blood vessels are formed to supply nutrients and cells to the injured area. Remodelling is the last step in which a scar tissue is formed mainly composed by collagen fibres.

The new stroma formed during this well-orchestrated process fills the wound space, and fibroblasts, macrophages and blood vessels subsequently invade the wounded area. Macrophages produce and secrete the growth factors required to stimulate angiogenesis[36] and fibroplasia, while blood vessels carry nutrients and oxygen to the new tissue mainly developed by fibroblasts. Scar tissue is mainly produced by the action of fibroblasts and the synthesis and production of collagen fibres, essentially collagen type I and III [37]. The 
production of elastin monomers is poor during wound healing, and the fibres obtained are organized in an aberrant manner, lacking any kind of order[38]. This lack of order contributes to the creation of a disturbed elastic network, which leads to a poorly elastic scar with poor resilience. The structure and integrity of the network of elastin fibres is a major factor governing the resilience, texture, quality and elasticity of skin [39]. Elastin can undergo hundreds of millions of cycles while maintaining its original behaviour and with almost no memory effect. However, its turnover is very low in healthy adults, with elastogenesis primarily occuring during the late fetal and early neonatal periods [40].

Elastogenesis is a process that rarely occurs under in vitro conditions, and only a few experiments in which new elastin was obtained have been reported[41-44]. These experiments were performed under conditions of continuous stressing movement of the artificial extracellular matrix (ECM), and the amount of elastin obtained in these artificial tissues was markedly lower than the amount and organization of the elastic network found in natural tissues. Indeed, when human skin is damaged, the subsequent wound healing process starts with a moderate inflammation process followed by the deposition of collagen, which subsequently forms a scar-like tissue with lower elasticity than the original tissue.

Since elastogenesis is a process that decreases with age[39], the development of new materials based on elastin or elastin-like polypeptides would appear to be a good approach. Following this line of reasoning, some researchers have focussed their efforts on producing elastin-based materials. Indeed, as far back as the early 1980's, Urry and others started to develop their so-called elastin-like polypeptides (ELPS) [45-47]. The subsequent development of recombinant techniques for polypeptide production opened the way to the construction of monodisperse and fully customisable polymers [48-50]. In this regard, Weiss et al. focused their efforts on the production of tropoelastin [51] which is a molecule with two different, alternating hydrophobic and hydrophilic domains. The hydrophobic domains are responsible 
for the elastic properties of the molecule, whereas the hydrophilic lysine-rich domain is involved in the crosslinking and polymerization process.

Within the next sections two types of elastin-based materials, tropoelastin based materials and elastin like materials, will be reviewed.

\section{Tropoelastin-based materials for wound healing}

Tropoelastin is a 60-72 kDa protein found in all vertebrates except cyclostomes. It is secreted from inside the cells to the cell surface where it tends to associate into fibrillar structures, thus denoting an inherent ability to self-assemble. Tropoelastin is characterized by alternate hydrophobic and hydrophilic domains within it structure. This alternation confers elasticity to the molecule and a smart thermal sensitiveness[52]. Below a certain temperature, known as the transition temperature $\left(T_{t}\right)$, tropoelastin remains a monomer with a length of approximately $15 \mathrm{~nm}$ [53], whereas weak interactions start to be established between hydrophobic domains above this $T_{t}$, with small spherule-like $(1-2 \mu \mathrm{m})$ aggregates going on to form a full-size coacervate $(2-6 \mu \mathrm{m})$. The process is reversible up to this point, with tropoelastin monomers being reformed after cooling below the $T_{t}$. Nevertheless, a nonreversible process starts if the temperature is maintained above $T_{t}$. Firstly, the coacervates collapse in a maturation process to finally give branched fibrillar structures due to the action of lysyl oxidases, which crosslink the coacervated tropoelastin molecules during the in vivo assembly process [54]. Coacervation of synthetic tropoelastin is a complex process that is affected by several factors, such as the number of hydrophobic domains, their sequence and the contextual arrangement of these domains. Moreover, hydrophilic domains, and their position and proportion with respect to hydrophobic domains, protein concentration, $\mathrm{pH}$ and ionic strength are important factors that have a marked influence on the coacervation process $[39,55-58]$. 
Given the complexity of this process, the preparation of macrostructures such as gels or fibres requires the use of crosslinkers or high $\mathrm{pH}$ conditions [54]. Thus, several methods have been developed to crosslink tropoelastin, although these typically require the use of organic chemicals such as glutaraldehyde (GA), hexamethylene diisocyanate (HMDI), disuccinimidyl suberate (DSS), and bis(sulfosuccinimidyl)suberate (BS3) [59], amongst others[27].

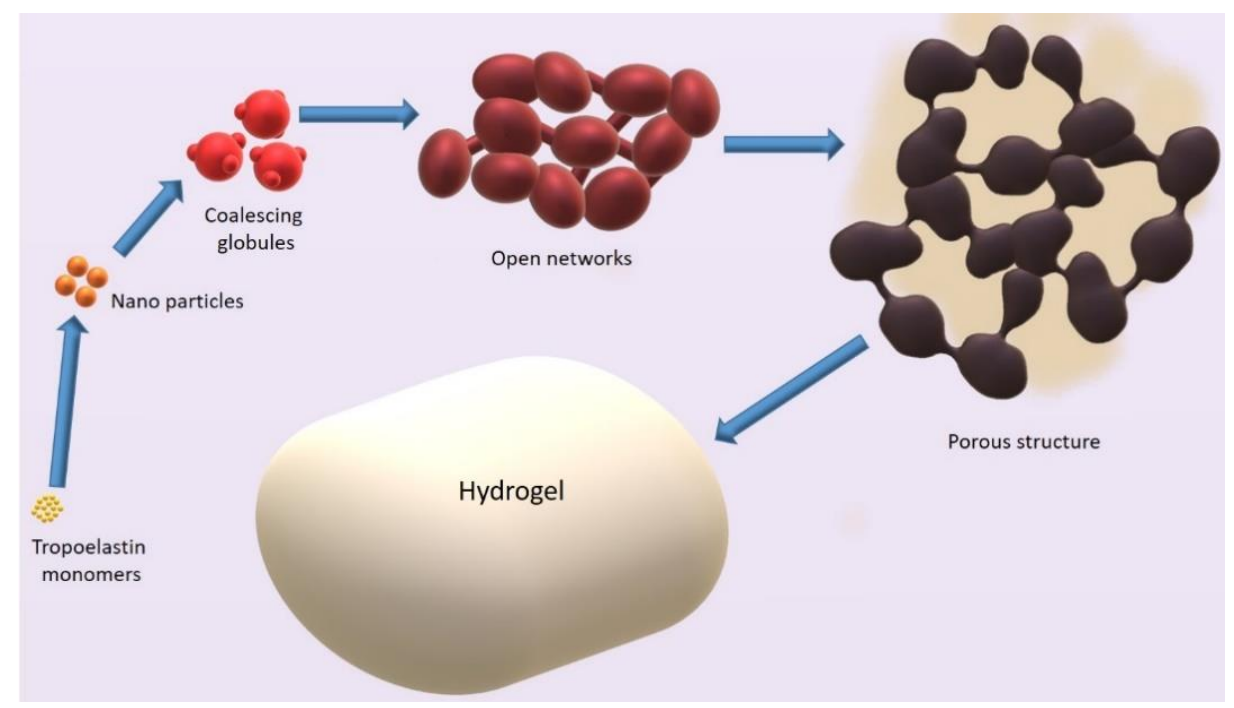

Fig. 2. Distinct stages in the formation of cross-linked tropoelastin hydrogels: tropoelastin monomers form discrete nanoparticles with a diameter of around $200 \mathrm{~nm}$. These particles subsequently merge to form larger globules, which coalesce into open linked networks that consolidate to form a porous structure comprising synthetic elastin hydrogels [59]

\subsection{Electrospun tropoelastin-based scaffolds}

Tropoelastin has been used in several different ways to obtain scaffolds that can be applied in wound-healing processes and dermal repair. Electrospinning, for example, enables the construction of scaffolds formed from nano- or microfibres, with different porosities, depending on the fibre diameter and the amount of material deposited during the electrospinning process. During electrospinning, tropoelastin is typically dissolved in a low boiling point solvent such as 1,1,1,3,3,3-hexafluoro-2-propanol (HFP). After fibre deposition, the resulting scaffold has to be cross-linked by reaction of the tropoelastin residues with at least one of the above-mentioned chemicals. Synthetic human elastin scaffolds have been 
obtained by electrospinning and subsequently crosslinked using the fumes from a $25 \%$ aqueous solution of GA. A close control of the mechanical properties and pore and fibre size can be obtained by modulating the electrospinning parameters. Dermal fibroblasts were found to be able to colonize these scaffolds, subsequently secreting collagen fibres and fibronectin throughout the synthetic material. In addition, new small blood vessel formation surrounding the constructs and a good in vivo interaction with adjacent tissues have also been reported [60].

The greatest issues that collagen, the major component in dermal tissues[61], and other natural materials applied in the wound healing field is contraction of the scaffold after cell colonization [62-64]. In the case of tropoelastin-based scaffolds, contraction of up to $30 \%$ of the original size was observed, which is a clear improvement with respect to the values of more than $50 \%$ in the case of electrospun collagen scaffolds [65]. Electrospun tropoelastin scaffolds have proved to be a promising support for human adipose-derived stem cells (HADSCs) as they speed up the wound-healing process by increasing the epithelial thickness $(51.9 \pm 11.27 \mu \mathrm{m})$ and wound closure with respect to untreated controls[66]. In this regard, Nivison-Smith et al. showed how human fibroblasts ( $\mathrm{Fb})$, human umbilical vein endothelial cells (HUVECs) and human coronary artery smooth muscle cells (HCASMCs), all of which are typically found in elastic tissues, attach and proliferate in electrospun scaffolds cross-linked with $\mathrm{HMDI}$ or GA, thus yielding fibres that persist for up to six months in aqueous environments at $37^{\circ} \mathrm{C}[67]$.

Elastin can be electrospun in combination with other natural or synthetic materials, such as collagen, silk, poly(lactic-co-glycolide), polycaprolactone, polyethylene oxide, gelatin, and polyglyconate, amongst others. As such, composite elastin-containing fibrous scaffolds have been explored by several research groups for use in various medical applications [68-74]. This plethora of combinations and applications underscores the versatility of the electrospinning 
technique and the good flexibility of synthetic elastin when combined with other materials.

Combinations of tropoelastin and collagen have been tested as rapid wound-closure scaffolds to improve skin regeneration. The resulting good mechanical properties, which are boosted by a clear collagen deposition after adequate fibroblast infiltration, combined with a mild inflammatory response and new angiogenesis that ensures a supply of oxygen and nutrients to the implanted scaffolds, make this approach a promising pathway to enhance the woundhealing process after trauma or burn injuries [73].
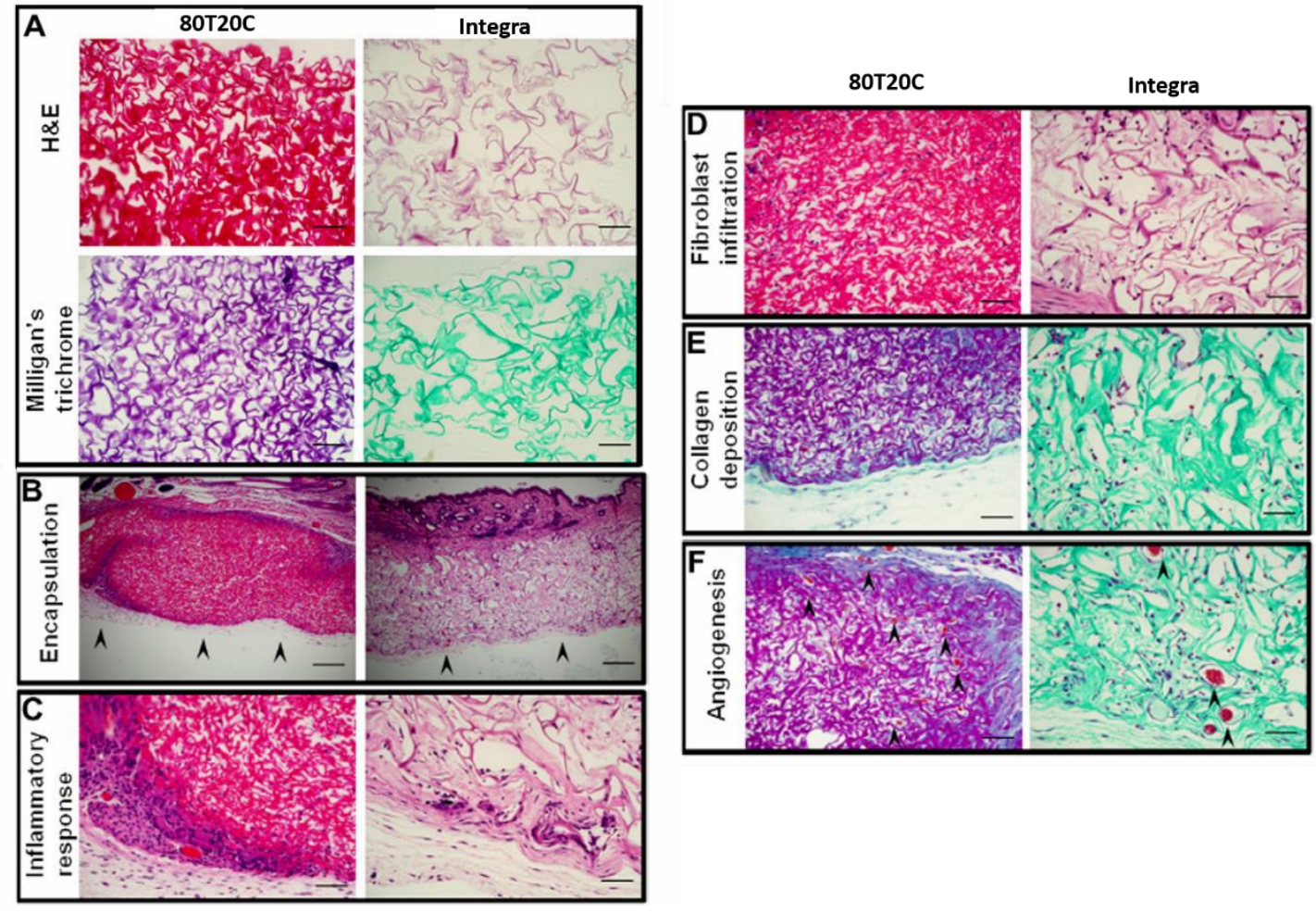

Fig. 3. The in vivo biological properties of $80 T 20 \mathrm{C}$ composite scaffolds compared to Integra at 6 weeks postsubcutaneous implantation in mice. (A) Scaffolds stained with H\&E and Milligan's trichrome prior to implantation. (B) Scaffold encapsulation. Arrowheads indicate a thin layer of fibroblasts encapsulating the scaffolds. (C) Mild inflammatory response. (D) Fibroblast infiltration. (E) Collagen deposition. (F) Blood vessels. Arrowheads indicate capillaries formed within the scaffolds. The scale bars are $50 \mu \mathrm{m}$ in all images except panel B, where they are 200 $\mu \mathrm{m}$. Image reproduced with permission from Rnjak-Kovacina et al (2012)

\subsection{Tropoelastin-based hydrogels}


Synthetic elastin hydrogels, 3D materials that can withstand a great amount of water incorporation while maintaining integrity[75], are excellent supports for tissue engineering uses that require some degree of elasticity. In the wound-healing field, significant effort has been invested to obtain optimal scaffolds that could lead to an effective and rapid restoration of damaged tissue $[76,77]$. As discussed previously for the case of electrospun scaffolds, hybrid tropoelastin/elastin hydrogels in combination with natural or synthetic materials can be obtained with mechanical properties ranging from hundreds to millions of Pascals and excellent cytocompatibility[78-81]. Vasconcelos et al produced for the first time silk-fibroin and elastin scaffolds for the treatment of burns[78], these scaffolds need to be cross-linked by the use of genipin, which in this precise case induces a conformational transition from random coil to $\beta$-sheet of silk-fibroin chains. The final proportion and composition of the scaffolds had a crucial effect on their physical properties that could be tuned to obtain hydrogels with different pore size, swelling ratios, degradation and release rates. The possibility that these materials offer as drug depots during the healing process was in vitro evaluated through the incorporation of antibacterial agents such as gentamicin. In vivo results pointed out that wounds treated with silk-fibroin/elastin dressings induced keratinocyte and fibroblast migration from the margins to the wound ground resulting in a completely closed and covered with new epithelium. This work demonstrate that biomaterials with higher presence of elastin yield more swellable, flexible and elastic scaffolds[78].

However, the need for chemicals such as GA, bis(sulfosuccinimidyl)suberate (BS3), methacrylic anhydride (MA), ethylene glycol diglycidyl ether (EGDE) or HMDI to crosslink the elastin and form a stable network is a key step that requires optimization of the proportions between polymers and crosslinkers. In addition, an exhaustive removal process is required after gel formation to avoid the toxic effects that unreacted chemicals or crosslinking conditions $(\mathrm{pH}$, temperature, solvents) that could be harmful for cells (in vitro) or in surrounding tissues (in vivo) [82-85]. 
Lin et al developed a method to form electrodeposited hydrogels made of silk-tropoelastin alloys. These alloys were prepared by enzymatic reaction between tyrosine residues[86]. In that work, authors correlate an enhanced proliferation of fibroblasts with increasing amounts of biologically active tropoelastin in the protein alloys.

An elastic sealant based on methacryloyl-substituted tropoelastin has been recently reported with a low inflammatory response by the host organism after subcutaneous implantation in rat model. MeTro, the name given to the biomaterial, is a photo-curable material based on recombinant tropoelastin. The mechanical properties of the material can be tuned by varying the polymer concentration or the methacrylation degree [87]. The biomaterial exhibits tuneable in vitro degradation by the action of matrix meatalloproteinase-2 (MMP-2) that have been combined with the MeTro polymers during the cure stage. Low concentration hydrogels showed faster degradation rates during in vivo experiments[88]. Previously to this work, Heinz et al conducted an exhaustive study about the degradation profiles of tropoelastin by the action of three MMPs (MMP-7, MMP-9 and MMP-12). Cleavages mainly befallen in the Cterminal and N-terminal regions of tropoelastin. That work exposed that all three MMPs have a clear preference for proline at $P_{3}, M M P-7$ shows a strong preference for leucine at $P_{1}{ }^{\prime}$, which is also well accepted by MMP-9 and MMP-12. Finally MMP-12 best tolerates bulky charged and aromatic amino acids at $\mathrm{P}_{1}{ }^{\prime}[89]$. From this work can be concluded that tropoelastin based materials can be degraded by the presence of these three MMPs that act over precise points on the aminoacid sequence of the tropoelastin as is represented in Fig 4. 


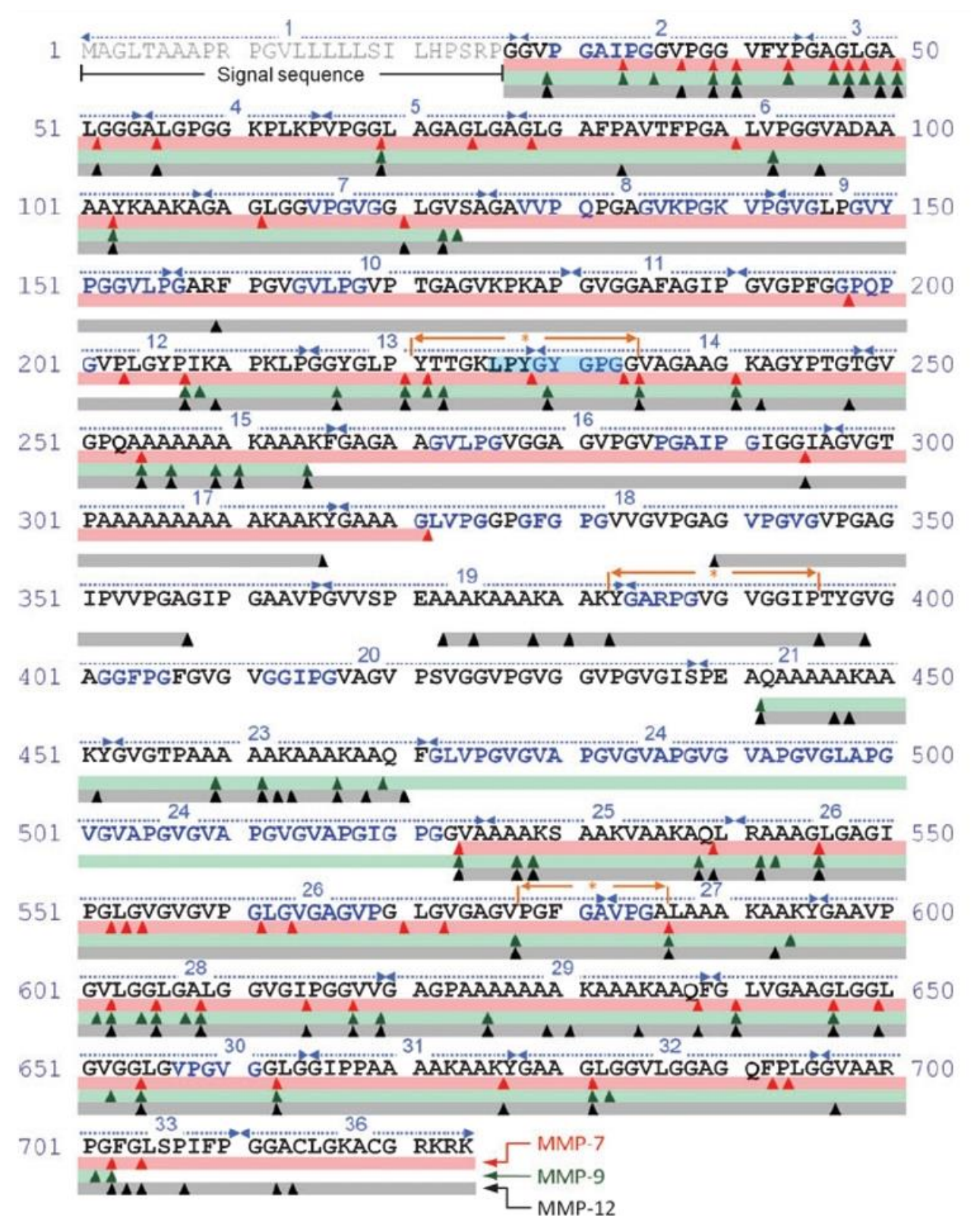

Fig. 4. Cleavage sites identified after digestion of human tropoelastin isoform 2 (SwissProt accession number: P15502-2) with MMP-7,MMP-9, and MMP-12. Cleavage sites are indicated by triangles (MMP-7, red; MMP-9, green; MMP-12, black), and all regions covered by peptides are labelled with solid lines (MMP-7, red; MMP-9, green; MMP-12, black). Bioactive sequences are shown in blue. The sequence of the octapeptide 226-233 used to model the interaction between a natural substrate and the active site of MMP-12 is marked with a blue bar. The sequences of three peptides containing GxxPG motifs (YTTGKLPYGYGPGG, YGARPGVGVGGIP, and PGFGAVPGA) used for bioactivity tests are labelled with asterisks and orange arrows. Reproduced with permission from[89].

This tropoelastin-based material was in vivo applied as sealant in small and large animal models (Fig 5). Concretely it was applied as sealant in lung injuries (rat and pig models). After 14 days, no air leakage occurred indicating an effective sealing of the injury. Wound was covered by dense fibrous tissue predominantly containing collagen, and a low presence of 
macrophages and lymphocytes in the wound repair area around the sealant indicating a low immunogenicity of the material. The sealant cover remained adherent to the defect site and the surrounding tissue.

Table 1: Mechanical properties of elastin-based scaffolds

\begin{tabular}{|c|c|c|c|c|c|c|}
\hline Material A & Material B & Proportion & Crosslinker & Scaffold & $\begin{array}{c}\text { Mechanical } \\
\text { properties (kPa) }\end{array}$ & REF \\
\hline Tropoelastin & $\alpha$-elastin & $\begin{array}{l}0 / 100 \\
25 / 75 \\
50 / 50 \\
100 / 0\end{array}$ & $\mathrm{GA}+\mathrm{CO}_{2}$ & Hydrogel & $\begin{array}{l}11^{*} \\
14^{*} \\
29 * \\
47^{*}\end{array}$ & {$[77]$} \\
\hline Tropoelastin & $\alpha$-elastin & $\begin{array}{l}25 / 75 \\
50 / 50 \\
100 / 0\end{array}$ & $\mathrm{GA}$ & Hydrogel & $\begin{array}{c}* \\
12^{*} \\
33^{*} \\
\end{array}$ & {$[77]$} \\
\hline Tropoelastin & & - & BS3 & Hydrogel & $220-280^{*}$ & {$[76]$} \\
\hline$\alpha$-elastin & & - & $\mathrm{HMDI}$ & Hydrogel & $11.0-19 * *$ & {$[90]$} \\
\hline Tropoelastin & Collagen & $\begin{array}{l}100 / 0 \\
80 / 20 \\
60 / 40 \\
50 / 50 \\
\end{array}$ & GA & Fibre $^{\#}$ & $\begin{array}{l}139^{*} \\
166^{*} \\
160^{*} \\
841^{*}\end{array}$ & {$[73]$} \\
\hline Elastin & Silk fibroin & $\begin{array}{l}0 / 100 \\
20 / 80 \\
50 / 50\end{array}$ & Genipin & Hydrogel & - & [78] \\
\hline Tropoelastin & & & UV ligth & Hydrogel & $\begin{array}{c}16.5-52.6^{*} \\
31.8-167.1^{* *}\end{array}$ & {$[88]$} \\
\hline
\end{tabular}

* Elastic modulus (Young's Modulus)

** Compressive modulus

\# Fibre diameter 2.1-6.5 $\mu \mathrm{m}$

GA: glutaraldehyde, BS3: bis(sulfosuccinimidyl)suberate, HDMI: hexamethylene diisocyanate,

\section{3. $\alpha$-Elastin-based hydrogels}

Other elastin derived products apart from tropoelastin can be found in wound healing literature. Here, we briefly describe the use of $\alpha$-elastin that usually is obtained by oxalic acid hydrolysis of the elastin[91, 92], the most recent applications of these materials in the wound healing field. $\alpha$-elastin based materials have been applied by Annabi et al to fabricate $\alpha$-elastin hydrogels using dense gas $\mathrm{CO}_{2}$ at high temperature to obtain different degrees of porosity for skin fibroblast (GM3348) culture[90, 93, 94]. They were able to obtain large pores within the gels that promote the scaffold colonization by the cells. Ito et al demonstrated that $\alpha$-elastin coacervates were suitable scaffolds for smooth muscle cells (SMCs) and endothelial cells (ECs) 

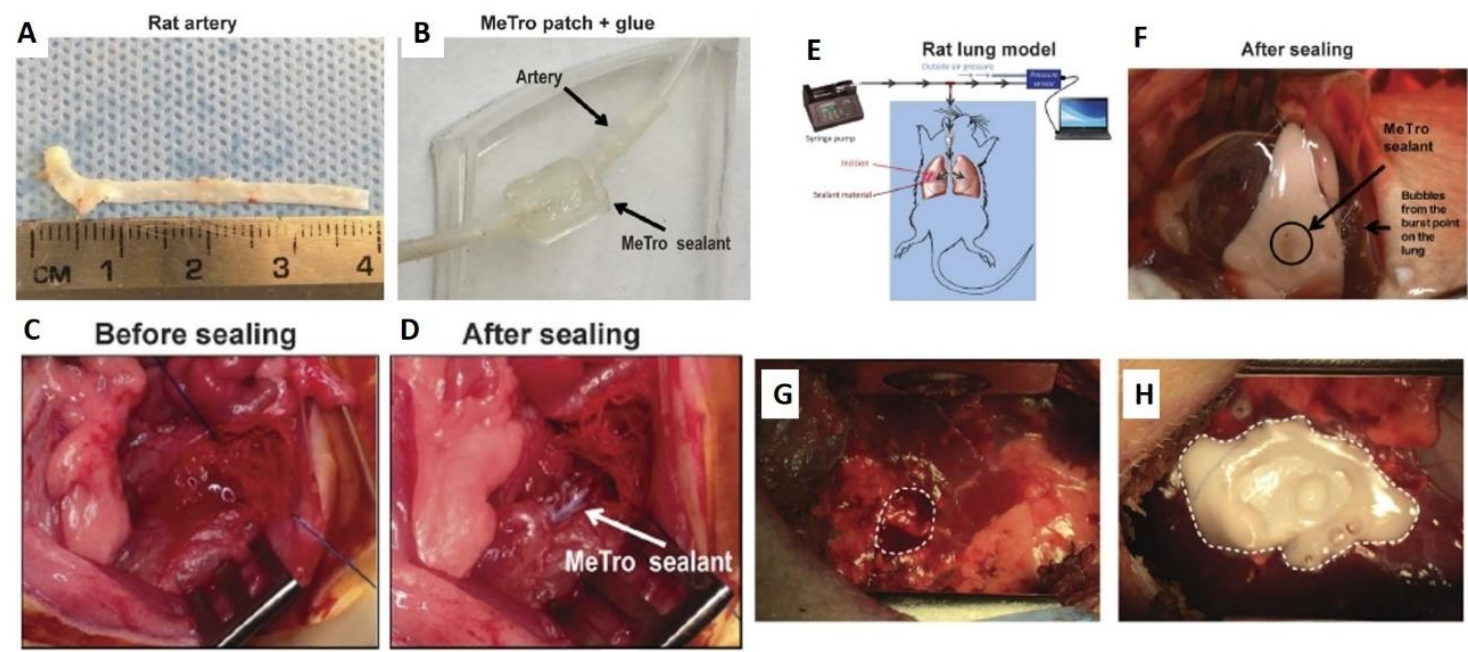

\section{After sealing}
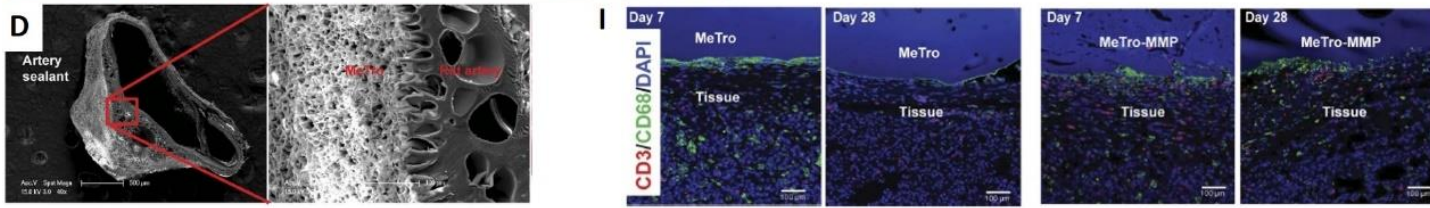

Fig. 5 (A, B) Ex vivo wound closure test using explanted rat aorta as a biological substrate for tissue adhesion. (A) An explanted aorta from a rat (about $4 \mathrm{~cm}$ in length). (B) A patch generated using the MeTro hydrogel and wrapped the artery tube segments. The connecting anastomosis points were further glued with MeTro. Arrows present the rat artery and MeTro sealant. (C, D) In vivo tests on rat arteries sealed by MeTro $(n=3)$. Operative sites $(C)$ before and (D) after sealing. White arrow presents the MeTro sealant on the artery. (E, F) In vivo tests on rat lungs sealed by MeTro. (E) Schematic diagram showing the experimental setup. (F) Image of the sealed lung pressurized with air, demonstrating that MeTro could adhere to the lung surface and seal the incision, but the lung tissue burst from other areas (the source of the bubbles) when pressures of $>5.5 \mathrm{kPa}$ were applied. G) In vivo sealing capacity of MeTro using a porcine lung incision model $(n=3)$.A right lung lobe is exposed through a small lateral thoracotomy, and a standardized defect is created [broken line in (G)] and sealed by applying and photocrosslinking the MeTro (20\% MeTro concentration with high methacryloyl substitution) sealant [dashed line in (H)]. (I) Fluorescent immunohistochemical analysis of the MeTro and MeTro-MMP sealants, showing no significant local lymphocyte infiltration (CD3) at days 7 and 28 for MeTro samples and at days 7 and 28 for MeTro-MMP samples. Also, the images exhibit remarkable macrophage (CD68) expression at day 7 but reduced expression at day 28 for MeTro and remained the same forMeTro-MMP samples. Green, red, and blue colours represent the macrophages, lymphocytes, and cell nuclei (DAPI), respectively. Reproduced with permission from [88]

\section{Elastin-like recombinamers (ELRs) as wound-healing materials}

Focusing in synthetized elastin-like materials, two different nomenclatures can be found, Elastin-like recombinamers (ELRs) or elastin-like polymers (ELPS). ELPs refer to polymers obtained by synthetic strategies that require chemical methods including the use of diverse precursors and solvents. Chemical synthesis of sort polypeptides based on elastin were successfully obtained by using standard chemical processes as demonstrated by Urry, Prasad 
and others[96,97], problems appear when complex structures or simply larger polymers want to be synthetized, obtaining mixtures of polymers with different molecular weight (high polydispersity)[98]. The use of recombinant DNA technologies, and the apparition of the ELR acronym, opened the door to overcome these problems with a close control over the global aminoacidic backbone of the polymers. The first apparition of this technology was developed by Cappello et al. in 1990 [99]. Nowadays, a "seamless cloning" technique is used to design the genes that codify the ELRs sequences. This technique is based on the use of the type Ils restriction endonuclease Eam1104I allowing the cleavage of DNA outside the recognition sequence and avoiding the introduction of extraneous nucleotides (nts) in the cloned sequence [100]. This method was first used successfully by Conticello and co-workers for the synthesis of ELR genes, suggesting that it could be a more rapid and efficient system for the bioproduction of protein polymers [101]. Different methods have been described in the literature for the bio-production of monodisperse ELRs with a desired amino acid sequence, from gene synthesis and expression in a bacterium up to the last purification step[102]. Synthesis of the corresponding polymeric ELR genes using iterative-recursive methods ensures that the designed polymer sequence is obtained during ligation with an extremely high control thanks to the unidirectional ligation mechanism [103]. Thus, engineered ELRs with the selected amino acid sequence that will provide the desired physical properties can be designed employing DNA technology and bioproduced on a large scale using Escherichia coli strains[104]

As can be deducted, ELPs and ELRs nomenclature refers to the same kind of polypeptides regardless their route of synthesis. So, from now on in this review and in order to unify nomenclatures, we will refer to this kind of polymers as ELRS

ELRs are tailor-made macromolecules based on the repetition of certain sequences from elastin, namely the pentapeptide valine-proline-glycine-valine-glycine (VPGVG), which is responsible for the elastic properties of the whole protein. ELRs are a family of genetically 
engineered polypeptides based on the elastin sequence VPGXG, where $X$ can be any amino acid except proline [25]. ELR sequences can be broadly altered to introduce specific functionalities using recombinant DNA methods [105]. The resulting polymers maintain similar properties to native elastin, such as an ability to self-assemble or thermoresponsive behaviour, whereby they undergo a reversible phase transition at the molecular level above a characteristic transition temperature (Tt) [106]. The backbone of ELRs can be precisely designed using DNA recombinant techniques, thereby allowing fine-tuning of the final Tt, which, amongst other advantages, allows easy purification methods consisting of temperature cycling above and below the Tt to be developed [25].

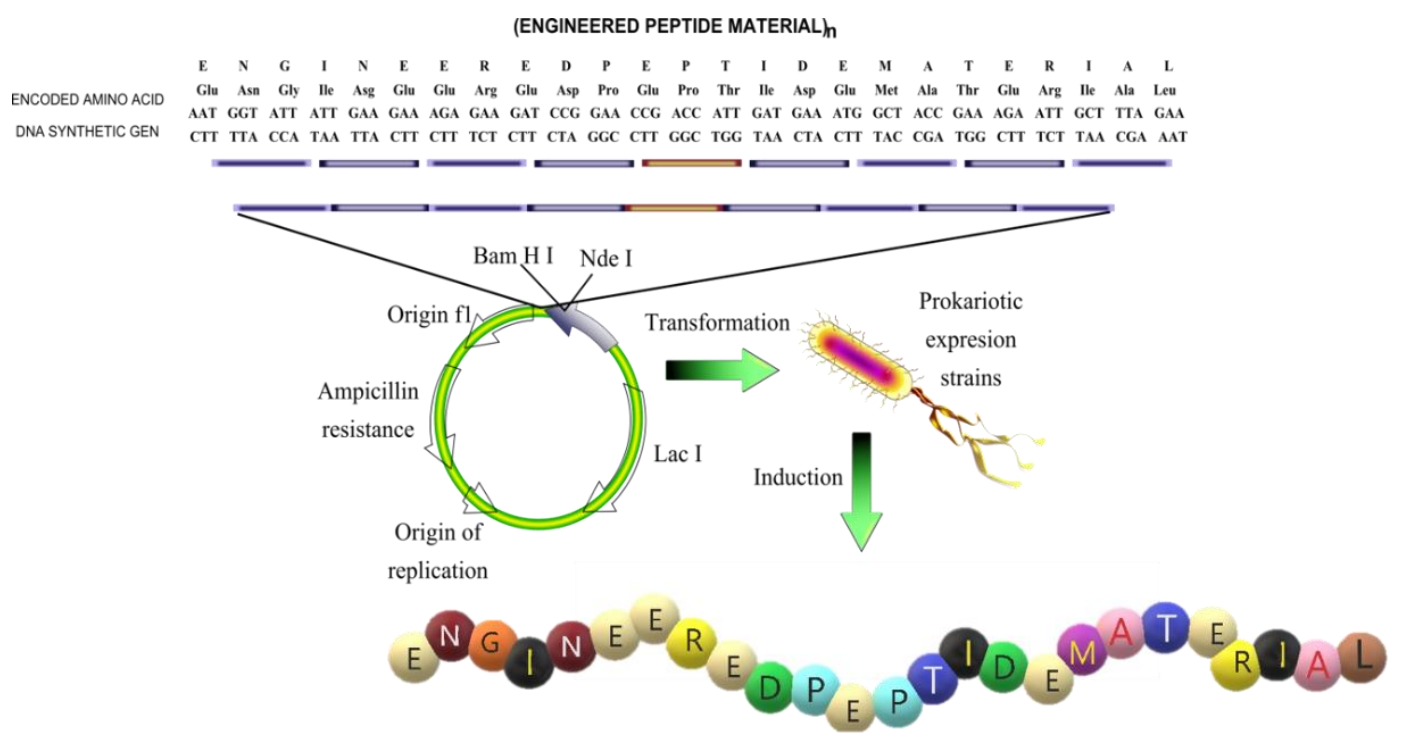

ELR

Fig. 6. Schematic representation of the design of the sequence and production of an elastin like recombinamer (ELR).

The design of ELRs has an important influence on their final application as different bioactivities and specific chemical functionalities can be incorporated at precise locations along the polymer backbone, thus allowing specific properties, such as biocompatibility and mechanical properties, to be tuned [107]. As a result, several biofunctionalities have been incorporated into the backbone of ELRs depending on their desired final applications. Perhaps the most frequent bioactive motif used in this kind of materials is the tripeptide arginine- 
glycine-aspartic acid (RGD) which was initially identified in fibronectin as a sequence that mediates in cell attachment [108]. Other bioactive sequences, such as arginine-glutamic acidaspartic acid-valine (REDV), which is a specific endothelial cell adhesion sequence[109], as well as motifs with a sensitivity to elastases (VGVAPG), have also been demonstrated to play crucial roles in different applications $[110,111]$.

In water-based solvents, ELRs undergo a self-assembly process governed by electrostatic interactions, folding hydrophobically and losing the clathrate water structures that dissolve the polypeptide at low temperatures. In this new state, the polymer chains are ordered into betaspirals and the temperature that defines this transition depends principally on the amino acid sequence and the molecular mass of the ELR [112]. The presence of polar residues in the $X$ position of the pentamer described above provokes an increase in the overall hydrophilicity, thereby increasing $\mathrm{Tt}$, whereas higher molecular weights produce the opposite effect, lowering Tt significantly [112].

When used as part of an artificial ECM, ELRs represent a solution for substituting or helping in the regeneration of damaged tissues [113]. This family of polypeptides could also provide structural support to the surrounding cells, thereby promoting a natural and adequate cell growth that aids complete integration of the scaffold within the surrounding natural tissue.

Thanks to their tuneable structure, ELRs can be processed from nano-micro scale to macroscopic hydrogels, passing through nano fibres (electrospinning) or micro drops (electrospray). This versatility allows the appropriate choice of ELRs for each specific application. Herein we will briefly review the most common ways to use ELRs in wound healing.

\subsection{ELR nanoparticles and coacervates}


The self-assembly process that ELRs undergo above their $T_{t}$ results in different degrees of organization depending on the polymer architecture. Thus, ELRs based on mono-blocks or nonsegregated alternating domains usually produce coacervates, while ELRs with a more complex structure in which hydrophobic and hydrophilic domains alternate along the backbone of the polypeptide results in nanoparticle formation. Both structures can be employed in wound healing therapies. In the mid-1980s, Senior et al. proved that ELPs carrying the hexamer VGVAPG (Val-Gly-Val-Ala-Pro-Gly) exhibit a chemotactic activity over fibroblast and monocytes [114], enhancing fibroblast proliferation and up-regulating the production of collagenase under in vitro conditions $[115,116]$. In contrast, VGVAPG suppresses the proliferation of keratinocytes and the pentamer VGVPG does not reduce their proliferation. Moreover, it seem that these sequences induce the terminal differentiation of cultured keratinocytes [117].

Thanks to the use of recombinant techniques, complex sequences such as growth factors (GF) can be included within the backbone of the ELRs or in some cases attached via chemical reaction to the peptidic sequence of the $\operatorname{ELRs}[118,119]$. Keratinocyte growth factor (KGF) or fibroblast growth factor-7 (FGF-7) are peptides included in the fibroblast growth factor category. Indeed, KGF is an important agent in epidermal morphogenesis and the woundhealing process [120]. This particular GF is mainly produced by cells of mesenchymal origin, such as smooth muscle cells, microvascular endothelial cells and fibroblasts. It is present at only very low levels in healthy tissues but is upregulated after injury [121], although its expression is reduced and delayed in diabetic models [122]. As such, in light of the proven benefits of KGF and ELPs alone, some researchers have fused both elements in a single molecule to obtain a synergic effect. Thus, Koria et al. observed that ELP-KGF nanoparticles produced a clear granulation in vivo. Although this effect was not particularly dramatic (an increase of $25 \%)$, it was nevertheless sufficient to induce and enhance the proliferation and migration of keratinocytes in the wounded area [119]. 
In high income countries, treatment of diabetic foot complications accounts for $15-25 \%$ of all diabetes healthcare resources [123], and in the USA, non-healing ulcers due to diabetes are still the leading cause of amputation, over and above amputations as a result of traumatic accidents [124]. Other GFs, such as epithelial growth factor (EGF), have shown excellent activity in the treatment of corneal epithelial lesions, burn injuries and acute surgical wounds [125-128], and, as such, could play a crucial role in the treatment of diabetic ulcers $[129,130]$. Indeed, viable and effective treatments are still needed to treat such complicated healing processes aggravated by diabetes[131]. As previously mentioned, diabetic models suggest a slower and deficient KGF expression during wound healing. Chronic wounds, such as diabetesrelated ulcers, produce increased levels of proteases, thus leading to a reduction in the lifetime of the growth factors needed for dermal regeneration[132, 133]. In such cases, fused ELP-GFs in the form of coacervate nanoparticles are able to remain active longer than GFs alone while increasing re-epithelization by way of an adequate granulation process. The mechanism of action for this wound healing seems to be related to local depots formed by the ELP-GF nanoparticles, which play a remarkable role in dermal regeneration[118]. Combined strategies using GF and cell-protecting peptides that prevents tissue injury, reduces inflammation and activates healing, fused to ELPs have also yielded promising results. Thus, the combination of KGF and ARA290, a cell-protecting peptide derived from the tertiary structure of erythropoietin (EPO), produces a synergic effect, thereby stimulating proliferation and migration of keratinocytes, along with an anti-apoptotic effect that enhances cell survival. Moreover, mixtures of ELPs fused with KGF or ARA290, locally delivered as suspension in fibrin gels, induce a higher vessel density and moderate granulation tissue formation that accelerates wound closure, thus resulting in epidermal regeneration and a thicker epidermis in a diabetic mouse model after 28 days [131] (Fig. 7). 
A
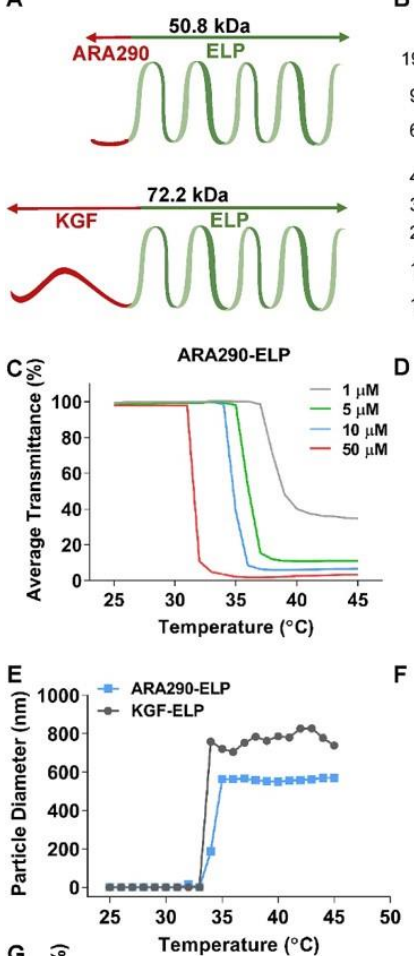

G

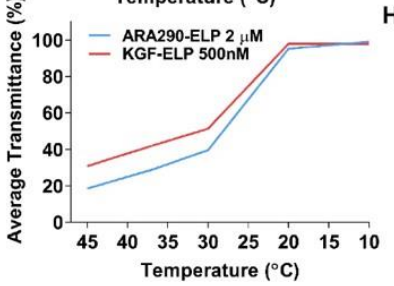

B
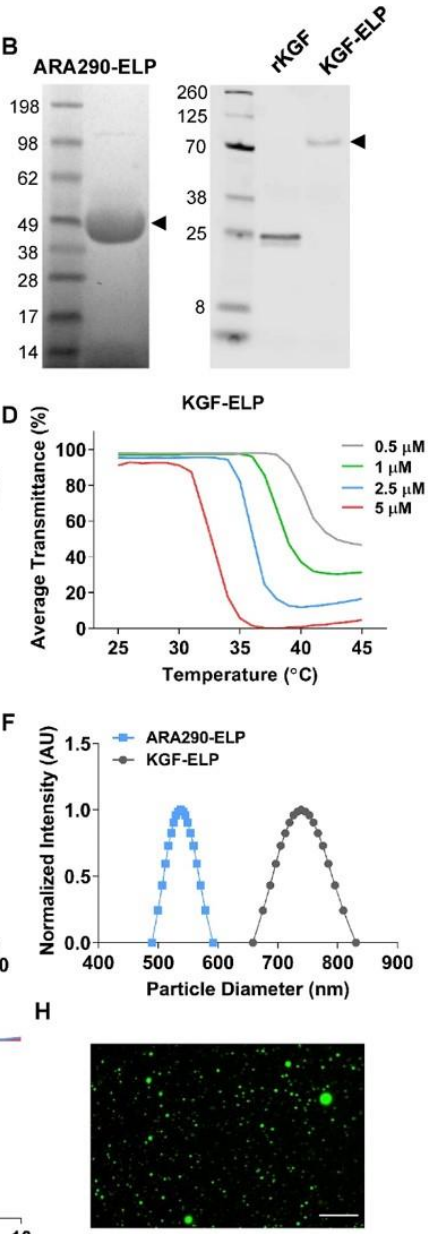

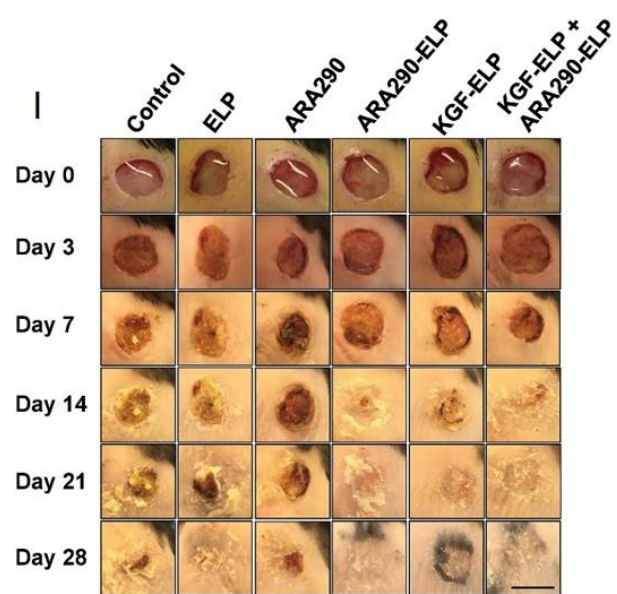

$\mathrm{J}$
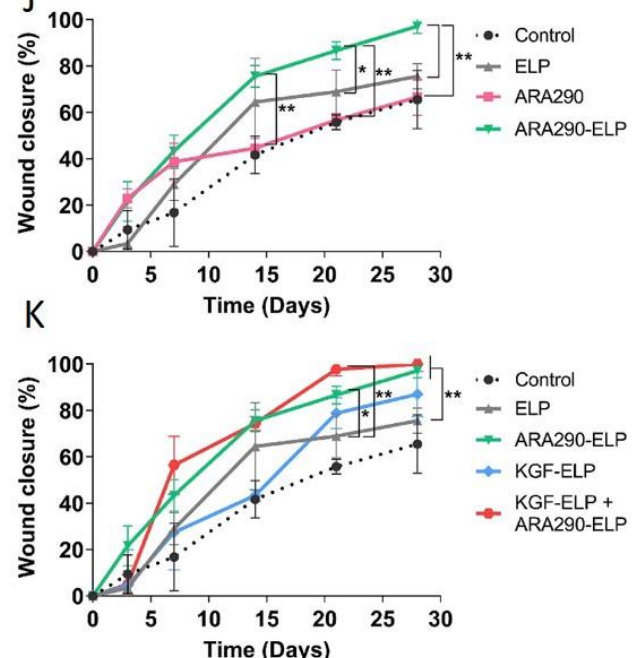

Fig. 7. Characterization of ARA290-ELP and KGF-ELP coacervates. (A) Schematic of ARA290-ELP and KGF-ELP fusion proteins. (B) Representative protein analysis showing purified ARA290-ELP and KGF-ELP after 3 rounds of inverse transition cycling. (C) and (D) Percent of average transmittance measurements at $350 \mathrm{~nm}$ over a range of increasing temperatures of ARA290-ELP $(1-50 \mu \mathrm{M})$ and KGF-ELP $(0.5-5 \mu \mathrm{M})$ samples, respectively. $N=3(\mathrm{E})$ Tt measurements via DLS over a range of temperatures at $25 \mu \mathrm{M}$ for ARA290-ELP and $5 \mu \mathrm{M}$ for KGF-ELP. (F) Lognormal aggregate size distributions at $25 \mu \mathrm{M}$ for ARA290-ELP and $5 \mu \mathrm{M}$ for KGF-ELP. (G) Percent of average transmittance measurements at $350 \mathrm{~nm}$ over a range of decreasing temperatures of ARA290-ELP $(2 \mu \mathrm{M})$ and KGF-ELP (500 nM) samples. $N=3(\mathrm{H})$ Confocal images of FITC-ELP $(2 \mu \mathrm{M})$ in PBS after coacervates induction at $45^{\circ} \mathrm{C}$ for $5 \mathrm{~min}$. Scale Bar is $50 \mu \mathrm{m}$. (I) Macroscopic analysis of diabetic wound healing. Multiple independent $10 \mathrm{~mm}$-diameter excisional biopsies were taken from the right and left dorsum of genetically diabetic mice. (I) Closure of wounds treated with empty fibrin gel (control) or fibrin gel containing ELP, ARA290, ARA290-ELP, KGF-ELP or combination of ARA290-ELP and KGF-ELP. Representative planetary pictures of wounds at day $0,3,7,14,21$ and 28 . (J) Wound closure progression along the treatment period. $(\mathrm{J})$ Wound closure 28 days after wound closing for each treatment group. $\mathrm{N}=5-8 /$ group, Scale bar is $1 \mathrm{~cm}$. One-way ANOVA with Dunnett's comparison to control or ELP group, ${ }^{*} p<0.05, * * p<0.01$. Reprinted with permission from [131]

In order to ensure a greater permanence of active molecules within the wounded area, thereby favouring a faster and more complete tissue regeneration, chemokines such as stromal cell-derived factor-1 (SDF1) [134] have also been fused to ELPs and locally intramuscular delivered into the target area as nanoparticles. Thus, Yeboah et al. showed that 
SDF1-ELP exerts a significant influence over HL-60 cell migration in vitro when applied as either monomers or nanoparticles. [135]. SDF1 was previously reported to be a vascularization inducer in human microvasculature endothelial cells [136] and the group of Yeboah observed a similar behaviour using HUVECs and SDF1-ELP nanoparticles [134] The same group demonstrated the bioactivity of SDF1-ELP nanoparticles locally delivered as suspension in fibrin gels in diabetic mice wound models. These nanoparticles proved to be stable in the presence of elastase, thus meaning that they could act as drug depots with possible applications in chronic wound treatment [137].

\subsection{ELR-based fibres}

ELR fibres can be obtained by wet spinning or electrospinning methods, thus resulting in fibres with different diameters. For instance, Qiu et al. described a wet spinning method to produce fibres with diameters in the range of few tens of micrometers [138], whereas with electrospinning systems, fibres with a wide range of diameters (100-450 nm) can be obtained simply by tuning the polymer concentration in the ELR solution [139]. Surprisingly, despite the excellent mechanical properties (table 2) in terms of tensile strength and Young's modulus[140], and the good biological properties of scaffolds constructed from electrospun ELRs [141], very few studies can be found in literature in which electrospun ELR-based scaffolds are used in the wound-healing field. The limited number of results regarding the good behaviour in terms of cell viability and proliferation of human skin fibroblasts on silkelastin-like peptide (SELP) fibres $[142,143]$ seem to indicate the possible use of such materials in dermal applications. Although synthetic elastin and tropoelastin have been electrospun to produce scaffolds for wound healing, as discussed above, the possible uses of pure elastin-like or hybrid ELRs and other materials have not yet been fully explored in dermal applications. The possibility of incorporating bioactive domains that enhance cell adhesion and proliferation, together with the tuneable porosity and fibre orientation that the electrospinning technique 
offers, appear to be excellent qualities that ELR- or SELR-based scaffolds could provide for application in wound-healing tissue engineering applications, at least a priori. Moreover, not only domains that enhance cell adhesion and proliferation can be incorporated to the ELRs structure. Recently, da Costa et al have fused the ABP-CM4 antimicrobial peptide from Bombix mori with an ELR to obtain an antimicrobial ELR (called CM4-A200). They have prepared fibres and thin films that have proved an excellent cytocompatibility (skin fibroblasts and keratinocytes) with high antimicrobial properties against Gram-positive and Gram-negative bacteria (staphylococcus aureus and Pseudomonas aeruginosa, respectively). Although in vivo experiments have not yet been performed with this CM4-A200, authors claim the great potential that this approach could have in the field of wound healing as, for instance, wound dressings for burn healing and skin reconstruction[144].

Table 2: Mechanical properties of ELR based fibres and elastin, collagen and spider silk

\begin{tabular}{|c|c|c|c|c|}
\hline Material & Tensile strength (MPa) & Young's modulus (MPa) & Strain at break (\%) & REF \\
\hline Elastin & 1.6 & $184 \pm 98$ & & {$[145]$} \\
\hline Spider Silk & $875-972$ & $11-13$ & $17-18$ & {$[146]$} \\
\hline Collagen & $8-12$ & $262 \pm 18$ & & {$[145]$} \\
\hline Tropoelastin & 13 & 289 & $80 \pm 10$ & {$[145]$} \\
\hline $\begin{array}{c}\text { Elastin/PDO } \\
\text { (1:1) }\end{array}$ & $0.9 \pm 0.1$ & $3.1 \pm 0.3$ & $45 \pm 4.0$ & {$[148]$} \\
\hline $\begin{array}{c}\text { Elastin/gelatin/ } \\
\text { Maxon }\end{array}$ & $0.76 \pm 0.07$ & $3.72 \pm 0.27$ & $71 \pm 20$ & {$[148]$} \\
\hline $\begin{array}{c}\text { Elastin/gelatin/ } \\
\text { Maxon }\end{array}$ & $2.11 \pm 0.53$ & $27.38 \pm 7.03$ & & {$[149]$} \\
\hline ELR & 35 & 1800 & $3.9 \pm 0.2$ & {$[150]$} \\
\hline ELR & $16.2 \pm 6.3$ & $700 \pm 150$ & $2.3 \pm 0.35$ & {$[150]$} \\
\hline ELR & $43.3 \pm 5.2$ & $1800 \pm 400$ & 7.9 & {$[151]$} \\
\hline SELR & 30.8 & 880 & & \\
\hline
\end{tabular}

\subsection{ELR-based hydrogels}

The first ELP-based hydrogels were described by Urry et al. in the early 1990s. In that case, a poly-VPGVG ELP was chemically crosslinked using $\gamma$-radiation to provide a stable matrix. Eleven tests, including mutagenicity, cytotoxicity, antigenicity, sensitization, pyrogenicity and haemolysis, amongst others, were performed to prove the biocompatibility of this family of 
hydrogels [152]. Since then, numerous other crosslinking methods have been reported for the formation of physical or chemical gels. This classification (physical or chemical gel) is based on the forces that maintain the structure of the formed hydrogels. Thus, physical hydrogels, for example, are stabilized by weak forces such as molecular entanglements, $\mathrm{H}$-bonding hydrophobic interactions or coulomb forces [153]. The resulting peptides are able to spontaneously self-assemble, thus leading to different structures [154, 155]. These peptides can be incorporated into more complex molecules to form crosslinking motifs such as $\beta$-sheets has allowed the entanglement properties of these macromolecules to be tuned to give different structures and, finally, physical hydrogels [156-159]. This versatility in the design and production of ELR-based materials enables the possibility of incorporating blocks from other proteins into the backbone of the ELRs. For instance, silk-like domains, mainly (GAGAGS) domains, have been extensively incorporated into ELRs to promote the formation of $\beta$-sheets that stabilize the integrity of physical hydrogels made from SELPs [160-163]. In addition, leucine zippers have been incorporated into the main structure of ELRs to create stable and reversible hydrogels [164].Although physical ELR-based hydrogels seem to have excellent properties, they have received little attention from researchers as tissue-engineering platforms. This could be due to the fact that, although such domains permit some degree of control over the mechanical properties, physical gels lack the desired strength required for tissue-engineering applications [165].

Chemical crosslinking produces hydrogels with enhanced mechanical properties and, although different options are available to chemically crosslink ELRs, almost all of them involve the amino group of the lateral chain of lysine residues. Among the crosslinking options, the use of chemicals is the most extended option. Indeed, chemical compounds such as glutaraldehyde (GTA) $[166,167]$ bis(sulfosuccinimidyl) suberate (BS3)[168], tris-succinimidyl aminotriacetate (TSAT) [169], $\beta$-[tris(hydroxymethyl)phosphino]propionic acid (THPP) $[170,171]$, pyrroloquinoline quinone (PQQ) [172], hydroxymethylphosphines (HMPs) [173] or 
hexamethylene diisocyanate (HMDI) [174], carbodiimides[175, 176], amongst others [167], are typical options for forming cross-linked networks of ELRs in a fast and efficient manner. However, although the use of the above mentioned compounds may be an excellent option to prepare preformed scaffolds, there are some discussion about the suitability of these compounds for the formation of injectable systems with embedded cells due to the inherent cytotoxicity of some of these compounds[175, 177, 178]. Despite the fact that radiation-based methods are also excellent options for the formation of ELR-based scaffolds [150], cytotoxicity issues may also appear if cells are to be introduced during hydrogel formation. Although genipin has been used as a cyto-compatible alternative [179], the long time required to complete crosslinking can produce cell sedimentation and a heterogeneous distribution of cells within the scaffold.

Transglutaminase-catalysed cross-linking allows cell encapsulation to occur under mild reaction conditions $[90,180,181]$, and substitution of the guest amino acid with cysteine in the repeating pentapeptide facilitates hydro-gelation due to the $\mathrm{H}_{2} \mathrm{O}_{2}$-mediated formation of disulfide bonds[168].

Table 3: Mechanical properties of ELR based scaffolds.

\begin{tabular}{|c|c|c|c|c|c|c|}
\hline Material A & Crosslinker & Proportion & Scaffold & $\begin{array}{c}\text { Mechanical } \\
\text { properties (kPa) }\end{array}$ & Application \\
\hline ELR & None & & Coacervate & $0.08^{+}$ & Mechanical characterization & {$[169]$} \\
\hline ELR & Transglutaminase & & Hydrogel & $0.26^{+}$ & Cartilage \\
\hline ELR & DSS & & Hydrogel & $120-230^{\&}$ & Vascular \\
\hline ELR & BS3 & & Hydrogel & $22-60^{\&}$ & Vascular \\
\hline ELR & TSAT & & Hydrogel & $8.0-10^{+}$ & Mechanical characterization & {$[184]$} \\
\hline ELR & None & & Fibre & $220-3000^{\$}$ & Mechanical characterization & {$[156]$} \\
\hline ELR & HMDI & & Hydrogel & $2.5-6.5^{+}$ & In vitro cell culture \\
\hline ELR & $\gamma$-irradiation & & Hydrogel & $10-200^{\$}$ & Mechanical characterization & {$[186]$} \\
\hline ELR & Genipin & & Hydrogel & $1800^{\$}$ & Mechanical characterization & {$[187]$} \\
\hline ELR & PQQ & & Hydrogel & $400^{\$}$ & Mechanical characterization & {$[187]$} \\
\hline ELR & None & $50 / 50$ & Hydrogel & $1-8^{+}$ & Mechanical characterization & {$[188]$} \\
\hline ELR & $\mathrm{C}_{6} \mathrm{H}_{7} \mathrm{NaO} / \mathrm{Cu}(\mathrm{II})$ & $50 / 50$ & Hydrogel & $1-9^{+}$ & Mechanical characterization & {$[189]$} \\
\hline SELR & GA & & Fibre & $1000-5000^{*}$ & Mechanical characterization & {$[138]$} \\
\hline
\end{tabular}

${ }^{+}$Complex shear modulus

\& Shear modulus

\$Tensile strength 
GA: glutaraldehyde, BS3: bis(sulfosuccinimidyl)suberate, HDMI: hexamethylene diisocyanate, TSAT: tris-succinimidyl aminotriacetate, DSS: disuccinimidyl suberate, PQQ: pyrroloquinoline quinone

Recently, Gonzalez de Torre et al. have developed a rapid, tuneable, biocompatible and cellfriendly crosslinking system based on a 1,3-dipolar cycloaddition reaction, a clear example of "click chemistry". This reaction requires the presence of azides and alkynes, which react orthogonally to form an irreversible covalent bond [188]. This rapid and biocompatible approach allows the homogeneous encapsulation of different cell types [189] and has proved its cytocompatibility with several cell lines and in different applications [111, 189-191].

ELR-based hydrogels have proved to be an excellent platform for fibroblast growth and proliferation [189, 192-194] although, once again, very little work has been published in the field of wound healing, with other applications such cartilage repair [179, 195], liver tissue engineering [196, 197], cardiovascular applications[190, 198] or ocular tissue engineering [199, 200] being the main focus of researchers' attention and efforts [201]. Recently, Staubli et al. have published a study in which ELR-based hydrogels, with or without bioactive sequences in their structure, behave in a very different manner under in vivo conditions. Thus, nonfunctionalized ELR-hydrogels produce scaffolds that cannot be rapidly degraded, which leads to a blockage of blood vessel infiltration and reduces the number of host cells that infiltrate into the scaffold. In contrast, functionalized ELR hydrogels containing general cell-adhesion sequences (RGD), specific sequences for endothelial cells (REDV) and sequences with elastase sensitivity (VGVAPG) support blood vessel infiltration, thus allowing rapid cell invasion of the scaffold (Fig. 8). In the early stages, this invasion is governed by the formation of cellular granulation tissue along with a mixture of neutrophils, lymphocytes, and macrophages that pave the way to a cellular scar-like tissue containing numerous small vessels [111]. A successful wound-healing process, or any other organ regeneration process, based on a bio-scaffold approach clearly depends on the immune response and the formation of new blood vessels 
that support host cell proliferation into the scaffold. Both angiogenesis and the immune reaction must be controlled depending on the specific application.
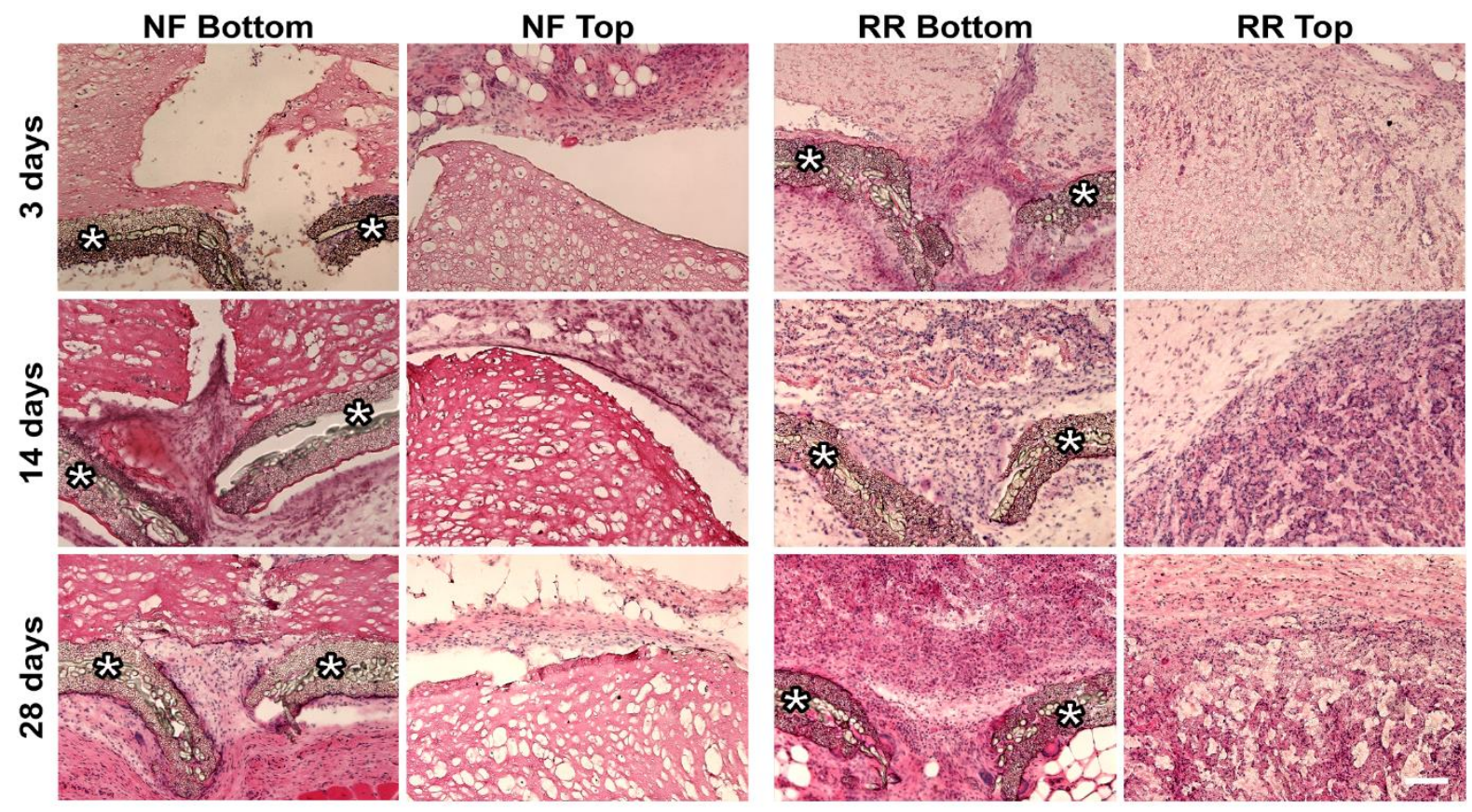

Fig. 8. In vivo host response to SVF cell-based ELR implants. Staining for hematoxylin and eosin of SVF cell-based constructs cultured in perfusion-based bioreactors in either NF (non-functionalized) or RR-ELR (functionalized) hydrogels after 3,14 or 28 days in vivo. Representative images of the bottom (in contact with the paper filter) and the top parts of the implants (in direct contact with the host tissue). The * marks the paper filter, which is located at the bottom of the implant. Scale bar $=100 \mu \mathrm{m}$. Reprinted with permission from[111].

\subsection{Surface treatment with ELRs}

Fibres, hydrogels, and nano- or microparticles are not the only ELR-based constructs to be applied in wound healing. Thus, Pierna et al. developed a method to biofunctionalize glass substrates by chemically attaching ELRs to their surfaces[202]. This methodology requires a chemical modification of the glass surfaces to incorporate alkynyl residues that can subsequently react with azide-bearing ELRs. This allowed the glass surfaces to be functionalized with thermosensitive ELRs, which change their conformation to expose or hide bioactive sequences that induce cell attachment. Thus, while the temperature remains above the $T_{t}$, the ELRs adopt a folded state that presents the bioactive sequences and allows cells to attach to their surfaces. When the temperature is decreased below the $T_{t}$, the ELR backbone changes to an extended conformation, thus hiding the bioactive sequences and triggering cell 
detachment. This study demonstrated the possibility of harvesting single cells or a complete cell layer without the need for chemical agents, and entire layers of fibroblasts were collected in this manner, thus opening up the possibility of applications in dermal regeneration[202].

Solvent casting of ELR-RGDs onto surfaces has been applied by the Pastor group to create bioactive substrates for the growth of human retinal pigment epithelial cells (hRPE). These hRPE cells attached to the ELR-RGD substrates and proliferated, while maintaining their morphology and RPE65 protein expression, for 360 hours, with clear differences with respect to controls being observed after only 24 hours. These studies suggest the possibility of using ELRs containing RGD sequences to fabricate a Brunch's membrane prosthesis for regeneration of the eye epithelium after illness or trauma [203, 204].

\section{Conclusion and future perspectives}

In this review, we attempted to summarize the advances in the application of elastin-based materials as platforms for wound healing. We have explored the possibilities that the two main families of synthetic elastin (synthetic tropoelastin and elastin like polymers) offer in this field. The tailored design and production of the elastin-derived materials is a versatile tool to introduce specific biofucntionalities and reactive groups in concrete positions within the backbone of the polymers. This tailored design allows a precise control over the architectural features to obtain the mechanical properties required in wound healing applications. The excellent biological, structural and assembly properties of the elastin-based materials have been harnessed to prepare nanoparticles, films, fibres and hydrogels that are able to instruct and respond to epithelial cells. Several methods to stabilize the scaffolds made of elastin like materials have been summarized in this review. Although many efforts to obtain a rapid, versatile and biocompatible crosslinking method have been done, only a few examples can be found of systems that do not require the use of potential cell-harmful chemicals. This should not be a problem if we do not want to fabricate cell-loaded or injectable systems, in which rapid and cyto-compatible in situ crosslinking methods are mandatory. 
In the case of tropoelastin-based materials for wound healing applications, many examples of scaffolds from electrospun fibres and hydrogels can be found, but if we talk about nanoparticles or functionalized surfaces only a few examples are described in literature. The possibilities that nanoparticles and hydrogels from ELPS offer in the field that we are concerned have been quite well explored. Nevertheless, only a few examples of scaffolds based on electrospun ELP-fibres can be found in literature. Therefore, in our humble opinion, although great advances have been achieved, there is still a long way to go in the development of adequate platforms based on elastin like materials for wound healing applications.

From the previous pages can be deducted that there is still room for improvement in the creation of systems based on elastin materials for wound healing therapies. The already existing materials need to be deeply tested in vivo. New and more elastic scaffolds that prevent from the contraction of the treated tissue and enhance the wound healing process have to be investigated as well as new strategies that focus in the antimicrobial properties of elastin-based scaffolds used as wound dressings. The use of recombinant materials opens the possibility to incorporate bioactive sequences that could help in the development of new biomaterials that can be applied in this field.

\section{Acknowledgements}

Works developed in this laboratory cited in the text were supported by the European Commission (ELASTISLET No 646075), the Ministerio de Economía y Competitividad of the Spanish Government (MAT2015-68901-R, MAT2016-78903-R, PCIN-2015-010) and the Junta de Castilla y León (VA015U16). 
[1] A.N. Gent, Elastomer, in, Encyclopædia Britannica, inc., Encyclopædia Britannica, 2016.

[2] R. McNeil Alexander, J. Gosline, D. W. Urry, F. W. Keeley, C.M. Kielty, F. Vollrath, R. Lewis, Svend Olav Anderson, J. H. Waite, P. R. Shewry, G. H. Thomas, D.E. Discher, P. Fratzl, J. Trinick, D. P. Knight, A. Bailey, A.S. Tatham, J. Vincent, Elastomeric Proteins, Structures, Biomechanical Properties, and Biological Roles, Cambridge University Press, 2003.

[3] M. Martino, T. Perri, A.M. Tamburro, Biopolymers and biomaterials based on elastomeric proteins, Macromolecular Bioscience, 2 (2002) 319-328.

[4] A.S. Tatham, P.R. Shewry, Elastomeric proteins: biological roles, structures and mechanisms, Trends in Biochemical Sciences, 25 (2000) 567-571.

[5] R.S.C. Su, Y. Kim, J.C. Liu, Resilin: Protein-based elastomeric biomaterials, Acta Biomaterialia, 10 (2014) 1601-1611.

[6] L. Li, S. Teller, R.J. Clifton, X. Jia, K.L. Kiick, Tunable mechanical stability and deformation response of a resilin-based elastomer, Biomacromolecules, 12 (2011) 2302-2310.

[7] J.N. Renner, K.M. Cherry, R.S. Su, J.C. Liu, Characterization of resilin-based materials for tissue engineering applications, Biomacromolecules, 13 (2012) 3678-3685.

[8] C.L. McGann, E.A. Levenson, K.L. Kiick, Resilin-Based Hybrid Hydrogels for Cardiovascular Tissue Engineering, Macromolecular Chemistry and Physics, 214 (2013) 203-213.

[9] E. Bini, D.P. Knight, D.L. Kaplan, Mapping domain structures in silks from insects and spiders related to protein assembly, J Mol Biol, 335 (2004) 27-40.

[10] C. Vepari, D.L. Kaplan, Silk as a Biomaterial, Progress in polymer science, 32 (2007) 9911007.

[11] S. Das, U. Bora, B.B. Borthakur, Applications of silk biomaterials in tissue engineering and regenerative medicine in: Silk Biomaterials for Tissue Engineering and Regenerative Medicine, Woodhead Publishing, 2014, pp. 41-77.

[12] A.T. Hodgkinson, A. Bayat, Silk for dermal tissue engineering in: Silk Biomaterials for Tissue Engineering and Regenerative Medicine, Woodhead Publishing, 2014, pp. 456-471.

[13] A.R. Murphy, I.S. Romero, Biochemical and biophysical properties of native Bombyx mori silk for tissue engineering applications in: Silk Biomaterials for Tissue Engineering and Regenerative Medicine, Woodhead Publishing, 2014, pp. 219-238.

[14] C. Patra, F.B. Engel, Silk for cardiac tissue engineering in: Silk Biomaterials for Tissue Engineering and Regenerative Medicine, Woodhead Publishing, 2014, pp. 429-455.

[15] M. Li, J. Li, Biodegradation behavior of silk biomaterials, in: Silk Biomaterials for Tissue Engineering and Regenerative Medicine, Woodhead Publishing, 2014, pp. 330-348.

[16] Z. Indik, H. Yeh, N. Ornstein-Goldstein, U. Kucich, W. Abrams, J.C. Rosenbloom, J. Rosenbloom, Structure of the elastin gene and alternative splicing of elastin mRNA: implications for human disease, Am J Med Genet, 34 (1989) 81-90.

[17] L. Debelle, A.M. Tamburro, Elastin: molecular description and function, International Journal of Biochemistry \& Cell Biology, 31 (1999) 261-272.

[18] J.M. P., H. W., Isolation and characterization of insoluble and kappa elastins, Robert, L , M Moczar And E Moczar (Ed) Frontiers Of Matrix Biology, 10 (1985) 92-129.

[19] P.M. Gallop, M.A. Paz, Posttranslational protein modifications, with special attention to collagen and elastin, Physiol Rev, 55 (1975) 418-487.

[20] M.R. A. Hinek, 67-kD elastin-binding protein is a protective "companion" of extracellular insoluble elastin and intracellular tropoelastin, The Journal of Cell Biology, 126 (1994) 563-574.

[21] L. Debelle, A.M. Tamburro, Elastin: molecular description and function, Int J Biochem Cell Biol, 31 (1999) 261-272.

[22] P. Brown-Augsburger, T. Broekelmann, J. Rosenbloom, R.P. Mecham, Functional domains on elastin and microfibril-associated glycoprotein involved in elastic fibre assembly, Biochem J, 318 ( Pt 1) (1996) 149-155. 
[23] P. Brown-Augsburger, C. Tisdale, T. Broekelmann, C. Sloan, R.P. Mecham, Identification of an elastin cross-linking domain that joins three peptide chains. Possible role in nucleated assembly, J Biol Chem, 270 (1995) 17778-17783.

[24] J.F. Almine, D.V. Bax, S.M. Mithieux, Elastin-based materials, Chemical Society Reviews, 39 (2010) 3371-3379.

[25] D.W. Urry, What sustains life? Consilient mechanisms for protein-based machines and materials, Springer-Verlag, New York, 2006.

[26] J.T. Powell, N. Vine, M. Crossman, On the accumulation of D-aspartate in elastin and other proteins of the ageing aorta, Atherosclerosis, 97 (1992) 201-208.

[27] G.C. Yeo, B. Aghaei-Ghareh-Bolagh, E.P. Brackenreg, M.A. Hiob, P. Lee, A.S. Weiss, Fabricated Elastin, Advanced Healthcare Materials, 4 (2015) 2530-2556.

[28] J.A.G. Derek J. Chadwick The Molecular Biology and Pathology of Elastic Tissues, Wiley, 2008.

[29] J.F. Almine, S.G. Wise, A.S. Weiss, Elastin signaling in wound repair, Birth Defects Research Part C: Embryo Today: Reviews, 96 (2012) 248-257.

[30] B.J. Larson, M.T. Longaker, H.P. Lorenz, Scarless fetal wound healing: a basic science review, Plast Reconstr Surg, 126 (2010) 1172-1180.

[31] G.H. Dostal, R.L. Gamelli, Fetal wound healing, Surg Gynecol Obstet, 176 (1993) 299-306.

[32] M.T. Longaker, Z.M. Peled, J. Chang, T.M. Krummel, Fetal wound healing: Progress report and future directions, Surgery, 130 (2001) 785-787.

[33] L.H. Yagi, L.M. Watanuki, C. Isaac, R. Gemperli, Y.M. Nakamura, P.R.S. Ladeira, Human fetal wound healing: a review of molecular and cellular aspects, European Journal of Plastic Surgery, 39 (2016) 239-246.

[34] J.D. Stroncek, W.M. Reichert, Overview of Wound Healing in Different Tissue Types, in: W.M. Reichert (Ed.) Indwelling Neural Implants: Strategies for Contending with the In Vivo Environment, CRC Press/Taylor \& Francis

Taylor \& Francis Group, LLC., Boca Raton (FL), 2008.

[35] A.J. Singer, R.A. Clark, Cutaneous wound healing, N Engl J Med, 341 (1999) 738-746.

[36] A.F. Karamysheva, Mechanisms of angiogenesis, Biochemistry. Biokhimiia, 73 (2008) 751762.

[37] G. Broughton, 2nd, J.E. Janis, C.E. Attinger, The basic science of wound healing, Plast Reconstr Surg, 117 (2006) 12s-34s.

[38] J. Rnjak-Kovacina, A.S. Weiss, The Role of Elastin in Wound Healing and Dermal Substitute Design, in: L.-P. Kamolz, D.B. Lumenta (Eds.) Dermal Replacements in General, Burn, and Plastic Surgery: Tissue Engineering in Clinical Practice, Springer Vienna, Vienna, 2013, pp. 57-66.

[39] B. Vrhovski, A.S. Weiss, Biochemistry of tropoelastin, Eur J Biochem, 258 (1998) 1-18.

[40] V.J. Uitto, H. Larjava, Extracellular matrix molecules and their receptors: an overview with special emphasis on periodontal tissues, Critical reviews in oral biology and medicine : an official publication of the American Association of Oral Biologists, 2 (1991) 323-354.

[41] Z.H. Syedain, M.T. Lahti, S.L. Johnson, P.S. Robinson, G.R. Ruth, R.W. Bianco, R.T. Tranquillo, Implantation of a Tissue-engineered Heart Valve from Human Fibroblasts Exhibiting Short Term Function in the Sheep Pulmonary Artery, Cardiovasc Eng Tech, 2 (2011) 101-112.

[42] T.C. Flanagan, J.S. Sachweh, J. Frese, H. Schnoring, N. Gronloh, S. Koch, R.H. Tolba, T. Schmitz-Rode, S. Jockenhoevel, In vivo remodeling and structural characterization of fibrinbased tissue-engineered heart valves in the adult sheep model, Tissue Eng Part A, 15 (2009) 2965-2976.

[43] R. Moreira, C. Neusser, M. Kruse, S. Mulderrig, F. Wolf, J. Spillner, T. Schmitz-Rode, S. Jockenhoevel, P. Mela, Tissue-Engineered Fibrin-Based Heart Valve with Bio-Inspired Textile Reinforcement, Advanced Healthcare Materials, 5 (2016) 2113-2121.

[44] A. Driessen-Mol, M.Y. Emmert, P.E. Dijkman, L. Frese, B. Sanders, B. Weber, N. Cesarovic, M. Sidler, J. Leenders, R. Jenni, J. Grunenfelder, V. Falk, F.P.T. Baaijens, S.P. Hoerstrup, 
Transcatheter implantation of homologous "off-the-shelf" tissue-engineered heart valves with self-repair capacity: long-term functionality and rapid in vivo remodeling in sheep, J Am Coll Cardiol, 63 (2014) 1320-1329.

[45] A.M. Tamburro, V. Guantieri, D.D. Gordini, Synthesis and Structural Studies of a Pentapeptide Sequence of Elastin. Poly (Val-Gly-Gly-Leu-Gly), Journal of Biomolecular Structure and Dynamics, 10 (1992) 441-454.

[46] D.W. Urry, Characterization of Soluble Peptides of Elastin by Physical Techniques, Methods in Enzymology, 82 (1982) 673-716.

[47] D.W. Urry, T.L. Trapane, H. Sugano, K.U. Prasad, Sequential Polypeptides of Elastin - Cyclic Conformational Correlates of the Linear Polypentapeptide, Journal of the American Chemical Society, 103 (1981) 2080-2089.

[48] A. Chilkoti, M.R. Dreher, D.E. Meyer, Design of thermally responsive, recombinant polypeptide carriers for targeted drug delivery, Advanced Drug Delivery Reviews, 54 (2002) 1093-1111.

[49] J.C. Rodriguez-Cabello, Smart elastin-like polymers, Adv Exp Med Biol, 553 (2004) 45-57.

[50] J.C. Rodriguez-Cabello, M. Pierna, A. Fernandez-Colino, C. Garcia-Arevalo, F.J. Arias, Recombinamers: combining molecular complexity with diverse bioactivities for advanced biomedical and biotechnological applications, Adv Biochem Eng Biotechnol, 125 (2011) 145179.

[51] S.L. Martin, B. Vrhovski, A.S. Weiss, Total synthesis and expression in Escherichia coli of a gene encoding human tropoelastin, Gene, 154 (1995) 159-166.

[52] S.G. Wise, A.S. Weiss, Tropoelastin, The International Journal of Biochemistry \& Cell Biology, 41 (2009) 494-497.

[53] A.W. Clarke, E.C. Arnspang, S.M. Mithieux, E. Korkmaz, F. Braet, A.S. Weiss, Tropoelastin massively associates during coacervation to form quantized protein spheres, Biochemistry, 45 (2006) 9989-9996.

[54] S.M. Mithieux, Y. Tu, E. Korkmaz, F. Braet, A.S. Weiss, In situ polymerization of tropoelastin in the absence of chemical cross-linking, Biomaterials, 30 (2009) 431-435.

[55] C.M. Bellingham, K.A. Woodhouse, P. Robson, S.J. Rothstein, F.W. Keeley, Self-aggregation characteristics of recombinantly expressed human elastin polypeptides, Biochim Biophys Acta, 1550 (2001) 6-19.

[56] A. Pepe, R. Flamia, D. Guerra, D. Quaglino, B. Bochicchio, I. Pasquali Ronchetti, A.M. Tamburro, Exon 26-coded polypeptide: an isolated hydrophobic domain of human tropoelastin able to self-assemble in vitro, Matrix Biol, 27 (2008) 441-450.

[57] W.J. Wu, B. Vrhovski, A.S. Weiss, Glycosaminoglycans mediate the coacervation of human tropoelastin through dominant charge interactions involving lysine side chains, J Biol Chem, 274 (1999) 21719-21724.

[58] K. Kaibara, Y. Akinari, K. Okamoto, Y. Uemura, S. Yamamoto, H. Kodama, M. Kondo, Characteristic interaction of $\mathrm{Ca} 2+$ ions with elastin coacervate: ion transport study across coacervate layers of alpha-elastin and elastin model polypeptide, (Val-Pro-Gly-Val-Gly)n, Biopolymers, 39 (1996) 189-198.

[59] Y. Tu, S.G. Wise, A.S. Weiss, Stages in tropoelastin coalescence during synthetic elastin hydrogel formation, Micron, 41 (2010) 268-272.

[60] J. Rnjak-Kovacina, S.G. Wise, Z. Li, P.K. Maitz, C.J. Young, Y. Wang, A.S. Weiss, Tailoring the porosity and pore size of electrospun synthetic human elastin scaffolds for dermal tissue engineering, Biomaterials, 32 (2011) 6729-6736.

[61] S.P. Zhong, Y.Z. Zhang, C.T. Lim, Tissue scaffolds for skin wound healing and dermal reconstruction, Wiley interdisciplinary reviews. Nanomedicine and nanobiotechnology, 2 (2010) 510-525.

[62] F.A. Auger, M. Rouabhia, F. Goulet, F. Berthod, V. Moulin, L. Germain, Tissue-engineered human skin substitutes developed from collagen-populated hydrated gels: clinical and fundamental applications, Med Biol Eng Comput, 36 (1998) 801-812. 
[63] I. Ono, T. Tateshita, M. Inoue, Effects of a collagen matrix containing basic fibroblast growth factor on wound contraction, J Biomed Mater Res, 48 (1999) 621-630.

[64] D.P. Berry, K.G. Harding, M.R. Stanton, B. Jasani, H.P. Ehrlich, Human wound contraction: collagen organization, fibroblasts, and myofibroblasts, Plast Reconstr Surg, 102 (1998) 124131; discussion 132-124.

[65] H.M. Powell, S.T. Boyce, Engineered human skin fabricated using electrospun collagen-PCL blends: morphogenesis and mechanical properties, Tissue Eng Part A, 15 (2009) 2177-2187.

[66] H. Machula, B. Ensley, R. Kellar, Electrospun tropoelastin for delivery of therapeutic adipose-derived stem cells to full-thickness dermal wounds, Advances in wound care, 3 (2014) 367-375.

[67] L. Nivison-Smith, J. Rnjak, A.S. Weiss, Synthetic human elastin microfibers: stable crosslinked tropoelastin and cell interactive constructs for tissue engineering applications, Acta biomaterialia, 6 (2010) 354-359.

[68] E.D. Boland, J.A. Matthews, K.J. Pawlowski, D.G. Simpson, G.E. Wnek, G.L. Bowlin, Electrospinning collagen and elastin: preliminary vascular tissue engineering, Frontiers in bioscience : a journal and virtual library, 9 (2004) 1422-1432.

[69] S.J. Lee, J.J. Yoo, G.J. Lim, A. Atala, J. Stitzel, In vitro evaluation of electrospun nanofiber scaffolds for vascular graft application, J Biomed Mater Res A, 83 (2007) 999-1008.

[70] J. Stitzel, J. Liu, S.J. Lee, M. Komura, J. Berry, S. Soker, G. Lim, M. Van Dyke, R. Czerw, J.J. Yoo, A. Atala, Controlled fabrication of a biological vascular substitute, Biomaterials, 27 (2006) 1088-1094.

[71] M. Li, M.J. Mondrinos, X. Chen, M.R. Gandhi, F.K. Ko, P.I. Lelkes, Co-electrospun poly(lactide-co-glycolide), gelatin, and elastin blends for tissue engineering scaffolds, J Biomed Mater Res A, 79 (2006) 963-973.

[72] X. Zhang, V. Thomas, Y.K. Vohra, Two ply tubular scaffolds comprised of proteins/poliglecaprone/polycaprolactone fibers, J Mater Sci Mater Med, 21 (2010) 541-549.

[73] J. Rnjak-Kovacina, S.G. Wise, Z. Li, P.K. Maitz, C.J. Young, Y. Wang, A.S. Weiss, Electrospun synthetic human elastin:collagen composite scaffolds for dermal tissue engineering, Acta biomaterialia, 8 (2012) 3714-3722.

[74] K.E. Swindle-Reilly, C.S. Paranjape, C.A. Miller, Electrospun poly(caprolactone)-elastin scaffolds for peripheral nerve regeneration, Progress in Biomaterials, 3 (2014) 1-8.

[75] M. McKenzie, D. Betts, A. Suh, K. Bui, L.D. Kim, H. Cho, Hydrogel-Based Drug Delivery Systems for Poorly Water-Soluble Drugs, Molecules, 20 (2015) 20397-20408.

[76] S.M. Mithieux, J.E. Rasko, A.S. Weiss, Synthetic elastin hydrogels derived from massive elastic assemblies of self-organized human protein monomers, Biomaterials, 25 (2004) 49214927.

[77] N. Annabi, S.M. Mithieux, A.S. Weiss, F. Dehghani, Cross-linked open-pore elastic hydrogels based on tropoelastin, elastin and high pressure CO2, Biomaterials, 31 (2010) 16551665.

[78] A. Vasconcelos, A.C. Gomes, A. Cavaco-Paulo, Novel silk fibroin/elastin wound dressings, Acta Biomaterialia, 8 (2012) 3049-3060.

[79] J. Mercuri, C. Addington, R. Pascal, S. Gill, D. Simionescu, Development and initial characterization of a chemically stabilized elastin glycosaminoglycan collagen composite shape memory hydrogel for nucleus pulposus regeneration, Journal of Biomedical Materials Research Part A, 102 (2014) 4380-4393.

[80] L. Buttafoco, P. Engbers-Buijtenhuijs, A.A. Poot, P.J. Dijkstra, W.F. Daamen, T.H. van Kuppevelt, I. Vermes, J. Feijen, First steps towards tissue engineering of small-diameter blood vessels: Preparation of flat scaffolds of collagen and elastin by means of freeze drying, Journal of Biomedical Materials Research Part B: Applied Biomaterials, 77B (2006) 357-368.

[81] M.J. Koens, K.A. Faraj, R.G. Wismans, J.A. van der Vliet, A.G. Krasznai, V.M. Cuijpers, J.A. Jansen, W.F. Daamen, T.H. van Kuppevelt, Controlled fabrication of triple layered and 
molecularly defined collagen/elastin vascular grafts resembling the native blood vessel, Acta biomaterialia, 6 (2010) 4666-4674.

[82] X. Lu, Y. Xu, C. Zheng, G. Zhang, Z. Su, Ethylene glycol diglycidyl ether as a protein crosslinker: a case study for cross-linking of hemoglobin, Journal of Chemical Technology and Biotechnology, 81 (2006) 767-775.

[83] M.J. van Luyn, P.B. van Wachem, L.O. Damink, P.J. Dijkstra, J. Feijen, P. Nieuwenhuis, Relations between in vitro cytotoxicity and crosslinked dermal sheep collagens, J Biomed Mater Res, 26 (1992) 1091-1110.

[84] P.B. van Wachem, M.J. van Luyn, L.H. Olde Damink, P.J. Dijkstra, J. Feijen, P. Nieuwenhuis, Biocompatibility and tissue regenerating capacity of crosslinked dermal sheep collagen, J Biomed Mater Res, 28 (1994) 353-363.

[85] H. Shin, B.D. Olsen, A. Khademhosseini, The mechanical properties and cytotoxicity of cellladen double-network hydrogels based on photocrosslinkable gelatin and gellan gum biomacromolecules, Biomaterials, 33 (2012) 3143-3152.

[86] Y. Lin, S. Wang, Y. Chen, Q. Wang, K.A. Burke, E.M. Spedden, C. Staii, A.S. Weiss, D.L. Kaplan, Electrodeposited gels prepared from protein alloys, Nanomedicine (Lond), 10 (2015) 803-814.

[87] N. Annabi, S.M. Mithieux, P. Zorlutuna, G. Camci-Unal, A.S. Weiss, A. Khademhosseini, Engineered cell-laden human protein-based elastomer, Biomaterials, 34 (2013) 5496-5505.

[88] N. Annabi, Y.-N. Zhang, A. Assmann, E.S. Sani, G. Cheng, A.D. Lassaletta, A. Vegh, B. Dehghani, G.U. Ruiz-Esparza, X. Wang, S. Gangadharan, A.S. Weiss, A. Khademhosseini, Engineering a highly elastic human protein-based sealant for surgical applications, Science Translational Medicine, 9 (2017) 1-14.

[89] A. Heinz, M.C. Jung, L. Duca, W. Sippl, S. Taddese, C. Ihling, A. Rusciani, G. Jahreis, A.S. Weiss, R.H.H. Neubert, C.E.H. Schmelzer, Degradation of tropoelastin by matrix metalloproteinases - cleavage site specificities and release of matrikines, FEBS Journal, 277 (2010) 1939-1956.

[90] N. Annabi, S.M. Mithieux, E.A. Boughton, A.J. Ruys, A.S. Weiss, F. Dehghani, Synthesis of highly porous crosslinked elastin hydrogels and their interaction with fibroblasts in vitro, Biomaterials, 30 (2009) 4550-4557.

[91] A.M. Tamburro, V. Guantieri, D. Daga-Gordini, G. Abatangelo, Conformational transitions of alpha-elastin, Biochim Biophys Acta, 492 (1977) 370-376.

[92] K. Kaibara, K. Sakai, K. Okamoto, Y. Uemura, K. Miyakawa, M. Kondo, Alpha-elastin coacervate as a protein liquid membrane: effect of $\mathrm{pH}$ on transmembrane potential responses, Biopolymers, 32 (1992) 1173-1180.

[93] J.B. Leach, J.B. Wolinsky, P.J. Stone, J.Y. Wong, Crosslinked alpha-elastin biomaterials: towards a processable elastin mimetic scaffold, Acta Biomater, 1 (2005) 155-164.

[94] N. Annabi, S.M. Mithieux, A.S. Weiss, F. Dehghani, The fabrication of elastin-based hydrogels using high pressure CO2, Biomaterials, 30 (2009) 1-7.

[95] S. Ito, S. Ishimaru, S.E. Wilson, Effect of coacervated alpha-elastin on proliferation of vascular smooth muscle and endothelial cells, Angiology, 49 (1998) 289-297.

[96] D.W. Urry, Entropic elastic processes in protein mechanisms. II. Simple (passive) and coupled (active) development of elastic forces, J Protein Chem, 7 (1988) 81-114.

[97] D. Urry, K.P.D. Williams, Biocompatibility of Tissue Analogues, in, CRC Press, Inc, 1985.

[98] D.T. McPherson, C. Morrow, D.S. Minehan, J. Wu, E. Hunter, D.W. Urry, Production and purification of a recombinant elastomeric polypeptide, G-(VPGVG)19-VPGV, from Escherichia coli, Biotechnol Prog, 8 (1992) 347-352.

[99] J. Cappello, J. Crissman, M. Dorman, M. Mikolajczak, G. Textor, M. Marquet, F. Ferrari, Genetic Engineering of Structural Protein Polymers, Biotechnology Progress, 6 (1990) 198-202. [100] K.A. Padgett, J.A. Sorge, Creating seamless junctions independent of restriction sites in PCR cloning, Gene, 168 (1996) 31-35. 
[101] R.A. McMillan, T.A.T. Lee, V.P. Conticello, Rapid Assembly of Synthetic Genes Encoding Protein Polymers, Macromolecules, 32 (1999) 3643-3648.

[102] J.C. Rodriguez-Cabello, A. Girotti, A. Ribeiro, F.J. Arias, Synthesis of genetically engineered protein polymers (recombinamers) as an example of advanced self-assembled smart materials, Methods Mol Biol, 811 (2012) 17-38.

[103] J.I. Won, A.E. Barron, A new cloning method for the preparation of long repetitive polypeptides without a sequence requirement, Macromolecules, 35 (2002) 8281-8287.

[104] L. Martin, F. Javier Arias, M. Alonso, C. Garcia-Arevalo, J.C. Rodriguez-Cabello, Rapid micropatterning by temperature-triggered reversible gelation of a recombinant smart elastinlike tetrablock-copolymer, Soft Matter, 6 (2010) 1121-1124.

[105] A. Girotti, A. Fernandez-Colino, I.M. Lopez, J.C. Rodriguez-Cabello, F.J. Arias, Elastin-like recombinamers: biosynthetic strategies and biotechnological applications, Biotechnol J, 6 (2011) 1174-1186.

[106] D.W. Urry, Physical Chemistry of Biological Free Energy Transduction As Demonstrated by Elastic Protein-Based Polymers, Journal of Physical Chemistry B, 101 (1997) 11007-11028.

[107] J.C. Rodríguez-Cabello, L. Martín, A. Girotti, C. García-Arévalo, F.J. Arias, M. Alonso, Emerging applications of multifunctional elastin-like recombinamers., Nanomedicine (London, England), 6 (2011) 111-122.

[108] S.E. D'Souza, M.H. Ginsberg, E.F. Plow, Arginyl-glycyl-aspartic acid (RGD): a cell adhesion motif, Trends Biochem Sci, 16 (1991) 246-250.

[109] J.A. Hubbell, S.P. Massia, N.P. Desai, P.D. Drumheller, Endothelial Cell-Selective Materials for Tissue Engineering in the Vascular Graft Via a New Receptor, Nat Biotech, 9 (1991) 568-572.

[110] J.C. Rodríguez-Cabello, M. Pierna, A. Fernández-Colino, C. García-Arévalo, F.J. Arias, Recombinamers: Combining Molecular Complexity with Diverse Bioactivities for Advanced Biomedical and Biotechnological Applications, in: G.S. Nyanhongo, W. Steiner, G. Gübitz (Eds.) Biofunctionalization of Polymers and their Applications, Springer Berlin Heidelberg, Berlin, Heidelberg, 2011, pp. 145-179.

[111] S.M. Staubli, G. Cerino, I. Gonzalez De Torre, M. Alonso, D. Oertli, F. Eckstein, K. Glatz, J.C. Rodríguez Cabello, A. Marsano, Control of angiogenesis and host response by modulating the cell adhesion properties of an Elastin-Like Recombinamer-based hydrogel, Biomaterials, 135 (2017) 30-41.

[112] D.W. Urry, D.C. Gowda, T.M. Parker, C.H. Luan, M.C. Reid, C.M. Harris, A. Pattanaik, R.D. Harris, Hydrophobicity Scale for Proteins Based on Inverse Temperature Transitions, Biopolymers, 32 (1992) 1243-1250.

[113] A. Girotti, J. Reguera, J.C. Rodríguez-Cabello, F.J. Arias, M. Alonso, A.M. Testera, Design and bioproduction of a recombinant multi(bio)functional elastin-like protein polymer containing cell adhesion sequences for tissue engineering purposes, Journal of Materials Science: Materials in Medicine, 15 (2004) 479-484.

[114] R.M. Senior, G.L. Griffin, R.P. Mecham, Val-Gly-Val-Ala-Pro-Gly, a repeating peptide in elastin, is chemotactic for fibroblasts and monocytes, The Journal of Cell Biology, 99 (1984) 870-874.

[115] A. Kamoun, J.M. Landeau, G. Godeau, J. Wallach, A. Duchesnay, B. Pellat, W. Hornebeck, Growth stimulation of human skin fibroblasts by elastin-derived peptides, Cell Adhes Commun, 3 (1995) 273-281.

[116] B. Brassart, P. Fuchs, E. Huet, A.J.P. Alix, J. Wallach, Conformational dependence of collagenase (matrix metalloproteinase-1) up-regulation by elastin peptides in cultured fibroblasts, Journal of Biological Chemistry, 276 (2001) 5222-5227.

[117] N. Fujimoto, S. Tajima, A. Ishibashi, Elastin peptides induce migration and terminal differentiation of cultured keratinocytes via $67 \mathrm{kDa}$ elastin receptor in vitro: $67 \mathrm{kDa}$ elastin receptor is expressed in the keratinocytes eliminating elastic materials in elastosis perforans serpiginosa, Journal of investigative dermatology, 155 (2000) 633-639. 
[118] S.R. MacEwan, A. Chilkoti, Applications of elastin-like polypeptides in drug delivery, Journal of Controlled Release, 190 (2014) 314-330.

[119] P. Koria, H. Yagi, Y. Kitagawa, Self-assembling elastin-like peptides growth factor chimeric nanoparticles for the treatment of chronic wounds, Proceedings of the National Academy of Sciences, 108 (2011) 1034-1039.

[120] S. Werner, Keratinocyte growth factor: a unique player in epithelial repair processes, Cytokine \& growth factor reviews, 9 (1998) 153-165.

[121] S. Werner, K.G. Peters, M.T. Longaker, Large induction of keratinocyte growth factor expression in the dermis during wound healing, Proceedings of the National Academy of Sciences, 89 (1992) 6896-6900.

[122] S. Werner, M. Breeden, G. Hübner, Induction of keratinocyte growth factor expression is reduced and delayed during wound healing in the genetically diabetic mouse, Journal of Investigative Dermatology, 103 (1994) 469-473.

[123] WHO/IDF, World Diabetes Day: too many people are losing lower limbs unnecessarily to diabetes, in, http://www.who.int/mediacentre/news/releases/2005/pr61/en/, 2005.

[124] A. American Diabetes, Economic Costs of Diabetes in the U.S. in 2012, Diabetes Care, 36 (2013) 1033-1046.

[125] J.D. Franklin, J.B. Lynch, Effects of topical applications of epidermal growth factor on wound healing. Experimental study on rabbit ears, Plast Reconstr Surg, 64 (1979) 766-770.

[126] K. Hori, C. Sotozono, J. Hamuro, K. Yamasaki, Y. Kimura, M. Ozeki, Y. Tabata, S. Kinoshita, Controlled-release of epidermal growth factor from cationized gelatin hydrogel enhances corneal epithelial wound healing, J Control Release, 118 (2007) 169-176.

[127] T. Kitazawa, S. Kinoshita, K. Fujita, K. Araki, H. Watanabe, Y. Ohashi, R. Manabe, The mechanism of accelerated corneal epithelial healing by human epidermal growth factor, Invest Ophthalmol Vis Sci, 31 (1990) 1773-1778.

[128] G.L. Brown, L.B. Nanney, J. Griffen, A.B. Cramer, J.M. Yancey, L.J. Curtsinger, 3rd, L. Holtzin, G.S. Schultz, M.J. Jurkiewicz, J.B. Lynch, Enhancement of wound healing by topical treatment with epidermal growth factor, N Engl J Med, 321 (1989) 76-79.

[129] A. Leonard, P. Koria, Growth factor functionalized biomaterial for drug delivery and tissue regeneration, Journal of Bioactive and Compatible Polymers, 32 (2017) 568-581.

[130] B. Gonul, M. Koz, G. Ersoz, B. Kaplan, Effect of EGF on the corneal wound healing of alloxan diabetic mice, Exp Eye Res, 54 (1992) 519-524.

[131] J. Devalliere, K. Dooley, Y. Yu, S.S. Kelangi, B.E. Uygun, M.L. Yarmush, Co-delivery of a growth factor and a tissue-protective molecule using elastin biopolymers accelerates wound healing in diabetic mice, Biomaterials, 141 (2017) 149-160.

[132] R. Moseley, J.E. Stewart, P. Stephens, R.J. Waddington, D.W. Thomas, Extracellular matrix metabolites as potential biomarkers of disease activity in wound fluid: lessons learned from other inflammatory diseases?, The British journal of dermatology, 150 (2004) 401-413.

[133] K.G. Harding, H.L. Morris, G.K. Patel, Science, medicine and the future: healing chronic wounds, Bmj, 324 (2002) 160-163.

[134] J.-i. Yamaguchi, K.F. Kusano, O. Masuo, A. Kawamoto, M. Silver, S. Murasawa, M. BoschMarce, H. Masuda, D.W. Losordo, J.M. Isner, T. Asahara, Stromal cell-derived factor-1 effects on ex vivo expanded endothelial progenitor cell recruitment for ischemic neovascularization, Circulation, 107 (2003) 1322-1328.

[135] A. Yeboah, T. Maguire, R. Schloss, F. Berthiaume, M.L. Yarmush, Stromal Cell-Derived Growth Factor-1 Alpha-Elastin Like Peptide Fusion Protein Promotes Cell Migration and Revascularization of Experimental Wounds in Diabetic Mice, Advances in Wound Care, 6 (2016) $10-22$.

[136] F. Mirshahi, J. Pourtau, H. Li, M. Muraine, V. Trochon, E. Legrand, J. Vannier, J. Soria, M. Vasse, C. Soria, SDF-1 activity on microvascular endothelial cells: consequences on angiogenesis in in vitro and in vivo models, Thromb Res, 99 (2000) 587-594. 
[137] A. Yeboah, R.I. Cohen, R. Faulknor, R. Schloss, M.L. Yarmush, F. Berthiaume, The development and characterization of SDF1 $\alpha$-elastin-like-peptide nanoparticles for wound healing, Journal of Controlled Release, 232 (2016) 238-247.

[138] W. Qiu, W. Teng, J. Cappello, X. Wu, Wet-spinning of recombinant silk-elastin-like protein polymer fibers with high tensile strength and high deformability, Biomacromolecules, 10 (2009) 602-608.

[139] M. Putzu, F. Causa, V. Nele, I.G. de Torre, Elastin-like-recombinamers multilayered nanofibrous scaffolds for cardiovascular applications, Biofabrication, 8 (2016) 1-14.

[140] D.B. Khadka, D.T. Haynie, Protein-and peptide-based electrospun nanofibers in medical biomaterials, Nanomedicine: Nanotechnology, Biology and Medicine, 8 (2012) 1242-1262.

[141] P.L. Benitez, J.A. Sweet, H. Fink, K.P. Chennazhi, S.V. Nair, A. Enejder, S.C. Heilshorn, Sequence-Specific Crosslinking of Electrospun, Elastin-Like Protein Preserves Bioactivity and Native-Like Mechanics, Advanced Healthcare Materials, 2 (2013) 114-118.

[142] R. Machado, A. da Costa, V. Sencadas, C. Garcia-Arévalo, C.M. Costa, J. Padrão, A. Gomes, S. Lanceros-Méndez, J. Rodríguez-Cabello, M. Casal, Electrospun silk-elastin-like fibre mats for tissue engineering applications, Biomedical Materials, 8 (2013) 1-13.

[143] B. Kinikoglu, J. Carlos Rodriguez-Cabello, O. Damour, V. Hasirci, A smart bilayer scaffold of elastin-like recombinamer and collagen for soft tissue engineering, Journal of Materials Science-Materials in Medicine, 22 (2011) 1541-1554.

[144] A. da Costa, A.M. Pereira, A.C. Gomes, J.C. Rodriguez-Cabello, V. Sencadas, M. Casal, R. Machado, Single step fabrication of antimicrobial fibre mats from a bioengineered proteinbased polymer, Biomed Mater, 12 (2017) 045011.

[145] M. Li, M.J. Mondrinos, M.R. Gandhi, F.K. Ko, A.S. Weiss, P.I. Lelkes, Electrospun protein fibers as matrices for tissue engineering, Biomaterials, 26 (2005) 5999-6008.

[146] T. Vehoff, A. Glišović, H. Schollmeyer, A. Zippelius, T. Salditt, Mechanical Properties of Spider Dragline Silk: Humidity, Hysteresis, and Relaxation, Biophysical Journal, 93 (2007) 44254432.

[147] M. MJ., B.C. Sell SA, B. WC., B. GL., Crosslinking electrospun polydioxanone-soluble elastin blends: material characterization, J Eng Fibers Fabr, 3 (2008) 1-10.

[148] X. Zhang, V. Thomas, Y.K. Vohra, In vitro biodegradation of designed tubular scaffolds of electrospun protein/polyglyconate blend fibers, J Biomed Mater Res B Appl Biomater, 89 (2009) 135-147.

[149] L. Huang, R.A. McMillan, R.P. Apkarian, B. Pourdeyhimi, V.P. Conticello, E.L. Chaikof, Generation of Synthetic Elastin-Mimetic Small Diameter Fibers and Fiber Networks, Macromolecules, 33 (2000) 2989-2997.

[150] K. Nagapudi, W.T. Brinkman, J.E. Leisen, L. Huang, R.A. McMillan, R.P. Apkarian, V.P. Conticello, E.L. Chaikof, Photomediated Solid-State Cross-Linking of an Elastin-Mimetic Recombinant Protein Polymer, Macromolecules, 35 (2002) 1730-1737.

[151] Y. Ner, J.A. Stuart, G. Whited, G.A. Sotzing, Electrospinning nanoribbons of a bioengineered silk-elastin-like protein (SELP) from water, Polymer, (2009).

[152] D.W. Urry, T.M. Parker, M.C. Reid, D.C. Gowda, Biocompatibility of the Bioelastic Materials, Poly(GVGVP) and Its $\gamma$-Irradiation Cross-Linked Matrix: Summary of Generic Biological Test Results, Journal of Bioactive and Compatible Polymers, 6 (1991) 263-282.

[153] J.C. Rodriguez-Cabello, I. Gonzalez de Torre, G. Pinedo, CHAPTER 19 Elastin-like Hydrogels and Self-assembled Nanostructures for Drug Delivery, in: Smart Materials for Drug Delivery: Volume 2, The Royal Society of Chemistry, 2013, pp. 180-198.

[154] E. Gazit, Self-assembled peptide nanostructures: the design of molecular building blocks and their technological utilization, Chemical Society Reviews, 36 (2007) 1263-1269.

[155] R.V. Ulijn, A.M. Smith, Designing peptide based nanomaterials, Chem Soc Rev, 37 (2008) 664-675. 
[156] K. Nagapudi, W.T. Brinkman, B.S. Thomas, J.O. Park, M. Srinivasarao, E. Wright, V.P. Conticello, E.L. Chaikof, Viscoelastic and mechanical behavior of recombinant protein elastomers, Biomaterials, 26 (2005) 4695-4706.

[157] J.C. Rodriguez-Cabello, S. Prieto, J. Reguera, F.J. Arias, A. Ribeiro, Biofunctional design of elastin-like polymers for advanced applications in nanobiotechnology, Journal of Biomaterials Science-Polymer Edition, 18 (2007) 269-286.

[158] D.W. Urry, Molecular Machines - How Motion and Other Functions of Living Organisms Can Result from Reversible Chemical-Changes, Angewandte Chemie-International Edition in English, 32 (1993) 819-841.

[159] D.W. Urry, Elastic molecular machines in metabolism and soft-tissue restoration, Trends Biotechnol, 17 (1999) 249-257.

[160] Z. Megeed, J. Cappello, H. Ghandehari, Genetically engineered silk-elastinlike protein polymers for controlled drug delivery, Advanced Drug Delivery Reviews, 54 (2002) 1075-1091.

[161] A. Nagarsekar, J. Crissman, M. Crissman, F. Ferrari, J. Cappello, H. Ghandehari, Genetic synthesis and characterization of $\mathrm{pH}$ - and temperature-sensitive silk-elastinlike protein block copolymers, Journal of Biomedical Materials Research, 62 (2002) 195-203.

[162] M. Haider, V. Leung, F. Ferrari, J. Crissman, J. Powell, J. Cappello, H. Ghandehari, Molecular engineering of silk-elastinlike polymers for matrix-mediated gene delivery: biosynthesis and characterization, Mol Pharm, 2 (2005) 139-150.

[163] A. Fernández-Colino, F.J. Arias, M. Alonso, J.C. Rodríguez-Cabello, Self-Organized ECMMimetic Model Based on an Amphiphilic Multiblock Silk-Elastin-Like Corecombinamer with a Concomitant Dual Physical Gelation Process, Biomacromolecules, 15 (2014) 3781-3793.

[164] A. Fernández-colino, F.J. Arias, M. Alonso, J.C. Rodriguez-cabello, Amphiphilic Elastin-Like Block co-Recombinamers Containing Leucine-Zippers : Cooperative Interplay between Both Domains Results in Injectable and Stable Hydrogels, Biomacromolecules, 16 (2015) 3389-3398.

[165] S.R. Macewan, A. Chilkoti, Elastin-like polypeptides: Biomedical applications of tunable biopolymers, Biopolymers, 94 (2010) 60-77.

[166] R.E. Sallach, W. Cui, J. Wen, A. Martinez, V.P. Conticello, Elastin-mimetic protein polymers capable of physical and chemical crosslinking, Biomaterials, 30 (2009) 409-422.

[167] M. Martino, A.M. Tamburro, Chemical synthesis of cross-linked poly(KGGVG), an elastinlike biopolymer, Biopolymers, 59 (2001) 29-37.

[168] N. Annabi, S.M. Mithieux, G. Camci-Unal, M.R. Dokmeci, A.S. Weiss, A. Khademhosseini, Elastomeric Recombinant Protein-based Biomaterials, Biochemical engineering journal, 77 (2013) 110-118.

[169] D.L. Nettles, A. Chilkoti, L.A. Setton, Applications of Elastin-like Polypeptides in Tissue Engineering, Advanced drug delivery reviews, 62 (2010) 1479-1485.

[170] D.W. Lim, D.L. Nettles, L.A. Setton, A. Chilkoti, Rapid cross-linking of elastin-like polypeptides with (hydroxymethyl)phosphines in aqueous solution, Biomacromolecules, 8 (2007) 1463-1470.

[171] D.L. Nettles, K. Kitaoka, N.A. Hanson, C.M. Flahiff, B.A. Mata, E.W. Hsu, A. Chilkoti, L.A. Setton, In situ crosslinking elastin-like polypeptide gels for application to articular cartilage repair in a goat osteochondral defect model, Tissue Eng Part A, 14 (2008) 1133-1140.

[172] A. Heinz, C.U. Schräder, S. Baud, F.W. Keeley, S.M. Mithieux, A.S. Weiss, R.H.H. Neubert, C.E.H. Schmelzer, Molecular-level characterization of elastin-like constructs and human aortic elastin, Matrix Biology, 38 (2014) 12-21.

[173] H. Wang, L. Cai, A. Paul, A. Enejder, S.C. Heilshorn, Hybrid elastin-like polypeptidepolyethylene glycol (ELP-PEG) hydrogels with improved transparency and independent control of matrix mechanics and cell ligand density, Biomacromolecules, 15 (2014) 3421-3428.

[174] M.B. Oliveira, W. Song, L. Martin, S.M. Oliveira, S.G. Caridade, M. Alonso, J.C. RodriguezCabello, J.F. Mano, Development of an injectable system based on elastin-like recombinamer particles for tissue engineering applications, Soft Matter, 7 (2011) 6426-6434. 
[175] D.W. Lim, D.L. Nettles, L.A. Setton, A. Chilkoti, Rapid Crosslinking of Elastin-like Polypeptides with Hydroxymethylphosphines in Aqueous Solution, Biomacromolecules, 8 (2007) 1463-1470.

[176] Y.-N. Zhang, R.K. Avery, Q. Vallmajo-Martin, A. Assmann, A. Vegh, A. Memic, B.D. Olsen, N. Annabi, A. Khademhosseini, A Highly Elastic and Rapidly Crosslinkable Elastin-Like Polypeptide-Based Hydrogel for Biomedical Applications, Advanced Functional Materials, 25 (2015) 4814-4826.

[177] J.E. Gough, C.A. Scotchford, S. Downes, Cytotoxicity of glutaraldehyde crosslinked collagen/poly(vinyl alcohol) films is by the mechanism of apoptosis, J Biomed Mater Res, 61 (2002) 121-130.

[178] A.f.T.S.a.D.R. (ATSDR), Toxicological Profile for Hexamethylene Diisocyanate., in: U.S.D.o.H.a.H. Services (Ed.), Public Health Service, U.S, Public Health Service, U.S, 1998.

[179] C. Hrabchak, J. Rouleau, I. Moss, K. Woodhouse, M. Akens, C. Bellingham, F. Keeley, M. Dennis, A. Yee, Assessment of biocompatibility and initial evaluation of genipin cross-linked elastin-like polypeptides in the treatment of an osteochondral knee defect in rabbits, Acta Biomaterialia, 6 (2010) 2108-2115.

[180] H. Kubo, T. Shimizu, M. Yamato, T. Fujimoto, T. Okano, Creation of myocardial tubes using cardiomyocyte sheets and an in vitro cell sheet-wrapping device, Biomaterials, 28 (2007) 3508-3516.

[181] W. Teng, J. Cappello, X. Wu, Physical crosslinking modulates sustained drug release from recombinant silk-elastinlike protein polymer for ophthalmic applications, Journal of Controlled Release, 156 (2011) 186-194.

[182] M.K. McHale, L.A. Setton, A. Chilkoti, Synthesis and in vitro evaluation of enzymatically cross-linked elastin-like polypeptide gels for cartilaginous tissue repair, Tissue Engineering, 11 (2005) 1768-1779.

[183] K. Di Zio, D.A. Tirrell, Mechanical properties of artificial protein matrices engineered for control of cell and tissue behavior, Macromolecules, 36 (2003) 1553-1558.

[184] K. Trabbic-Carlson, L.A. Setton, A. Chilkoti, Swelling and mechanical behaviors of chemically cross-linked hydrogels of elastin-like polypeptides, Biomacromolecules, 4 (2003) 572-580.

[185] L. Martin, M. Alonso, A. Girotti, F.J. Arias, J.C. Rodriguez-Cabello, Synthesis and characterization of macroporous thermosensitive hydrogels from recombinant elastin-like polymers, Biomacromolecules, 10 (2009) 3015-3022.

[186] J. Lee, C.W. Macosko, D.W. Urry, Mechanical Properties of Cross-Linked Synthetic Elastomeric Polypentapeptides, Macromolecules, 34 (2001) 5968-5974.

[187] S. Vieth, C.M. Bellingham, F.W. Keeley, S.M. Hodge, D. Rousseau, Microstructural and tensile properties of elastin-based polypeptides crosslinked with Genipin and pyrroloquinoline quinone, Biopolymers, 85 (2007) 199-206.

[188] I. González de Torre, M. Santos, L. Quintanilla, A. Testera, M. Alonso, J.C. Rodríguez Cabello, Elastin-like recombinamer catalyst-free click gels: Characterization of poroelastic and intrinsic viscoelastic properties, Acta Biomaterialia, 10 (2014) 2495-2505.

[189] A. Testera, A. Girotti, I. de Torre, L. Quintanilla, M. Santos, M. Alonso, J. RodríguezCabello, Biocompatible elastin-like click gels: design, synthesis and characterization, Journal of Materials Science: Materials in Medicine, 26 (2015) 1-13.

[190] I. González de Torre, F. Wolf, M. Santos, L. Rongen, M. Alonso, S. Jockenhoevel, J.C. Rodríguez-Cabello, P. Mela, Elastin-like recombinamer-covered stents: Towards a fully biocompatible and non-thrombogenic device for cardiovascular diseases, Acta Biomaterialia, 12 (2015) 146-155.

[191] M.P. Sousa, I. Gonzalez de Torre, M.B. Oliveira, J.C. Rodríguez-Cabello, J.F. Mano, Biomimetic click assembled multilayer coatings exhibiting responsive properties, Materials Today Chemistry, 4 (2017) 150-163. 
[192] N. Annabi, K. Tsang, S.M. Mithieux, M. Nikkhah, A. Ameri, A. Khademhosseini, A.S. Weiss, Highly Elastic Micropatterned Hydrogel for Engineering Functional Cardiac Tissue, Advanced functional materials, 23 (2013) 1-18.

[193] H. Wang, L. Cai, A. Paul, A. Enejder, S.C. Heilshorn, Hybrid Elastin-like PolypeptidePolyethylene Glycol (ELP-PEG) Hydrogels with Improved Transparency and Independent Control of Matrix Mechanics and Cell Ligand Density, Biomacromolecules, 15 (2014) 34213428.

[194] D.W. Lim, D.L. Nettles, L.A. Setton, A. Chilkoti, In situ cross-linking of elastin-like polypeptide block copolymers for tissue repair, Biomacromolecules, 9 (2007) 222-230.

[195] I.L. Moss, L. Gordon, K.A. Woodhouse, C.M. Whyne, A.J. Yee, A novel thiol-modified hyaluronan and elastin-like polypetide composite material for tissue engineering of the nucleus pulposus of the intervertebral disc, Spine (Phila Pa 1976), 36 (2011) 1022-1029.

[196] A.V. Janorkar, P. Rajagopalan, M.L. Yarmush, Z. Megeed, The use of elastin-like polypeptide-polyelectrolyte complexes to control hepatocyte morphology and function in vitro, Biomaterials, (2008).

[197] M. Swierczewska, C.S. Hajicharalambous, A.V. Janorkar, Cellular response to nanoscale elastin-like polypeptide polyelectrolyte multilayers, Acta biomaterialia, 4 (2008) 827-837.

[198] J.C. Liu, D.A. Tirrell, Cell response to RGD density in cross-linked artificial extracellular matrix protein films, Biomacromolecules, 9 (2008) 2984-2988.

[199] A. Girotti, J. Reguera, J.C. Rodriguez-Cabello, F.J. Arias, M. Alonso, A. Matestera, Design and bioproduction of a recombinant multi(bio)functional elastin-like protein polymer containing cell adhesion sequences for tissue engineering purposes, J Mater Sci Mater Med, 15 (2004) 479-484.

[200] H. Martínez-Osorio, M. Juárez-Campo, Y. Diebold, A. Girotti, M. Alonso, F.J. Arias, J.C. Rodríguez-Cabello, C. García-Vázquez, M. Calonge, Genetically Engineered Elastin-Like Polymer as a Substratum to Culture Cells from the Ocular Surface, Current Eye Research, 34 (2009) 4856.

[201] D. Nettles, A. Chilkoti, L. Setton, Applications of elastin-like polypeptides in tissue engineering, Advanced Drug Delivery Reviews, 62 (2010) 1479-1485.

[202] M. Pierna, M. Santos, F. Arias, M. Alonso, J. Rodriguez-Cabello, Efficient cell and cellsheet harvesting based on smart surfaces coated with a multifunctional and self-organizing Elastin-Like Recombinamer, Biomacromolecules, 14 (2013) 1893-1903.

[203] A.K. Singh, G.K. Srivastava, L. Martin, M. Alonso, J.C. Pastor, Bioactive substrates for human retinal pigment epithelial cell growth from elastin-like recombinamers, J Biomed Mater Res A, 102 (2013) 639-646.

[204] G.K. Srivastava, L. Martin, A.K. Singh, I. Fernandez-Bueno, M.J. Gayoso, M.T. GarciaGutierrez, A. Girotti, M. Alonso, J.C. Rodriguez-Cabello, J.C. Pastor, Elastin-like recombinamers as substrates for retinal pigment epithelial cell growth, Journal of Biomedical Materials Research Part A, 97A (2011) 243-250. 